\title{
El Salón Norte del Palacio al-Badi' de Marrakech: Estudio arqueológico e hipótesis sobre su forma original
}

\author{
The North Hall of al-Badi' Palace in Marrakech: Archaeological study \\ and hypothesis about its original form
}

\author{
Antonio Almagro \\ Laboratorio de Arqueología y Arquitectura de la Ciudad (LAAC) \\ Escuela de Estudios Árabes, CSIC. Granada. \\ E-mail: aalmagro@eea.csic.es
}

\section{RESUMEN}

El palacio al-Badi de Marrakech es uno de los monumentos arquitectónicos más impresionantes del occidente islámico, cuya construcción se remonta a finales del siglo XVI, y que tras breve vida pasó a un estado de forzada austeridad al ser sistemáticamente expoliado. Sus colosales dimensiones aún confieren a sus ruinas un carácter monumental que recuerda al de algunas construcciones de la antigüedad, que aún nos evocan su pasada exuberancia ornamental a través de detalles y vestigios. Basado en un cuidadoso análisis de sus restos y en el estudio comparativo con otros edificios contemporáneos y anteriores se propone una hipótesis sobre su forma original, que a su vez nos ayuda a entender algunas de sus funciones y significados. Para el estudio del Salón Norte, que por su tamaño y situación debió ser uno de los principales espacios del palacio, hemos seguido una metodología similar a la de otros trabajos ya realizados en este conjunto que incluyen un detallado levantamiento, el examen de las trazas aún visibles en las estructuras conservadas, el estudio comparativo con otros edificios coetáneos, así como el análisis de fuentes gráficas y escritas.
\end{abstract}

Palabras clave: arquitectura sa'adí, estudio de paramentos, qubba, bahw.

\section{ABSTRACT}

The al-Badi' Palace in Marrakech is one of the most impressive monuments of western Islamic architecture, dating from the end of the sixteen century, later led to a state of forced austerity due to its systematic looting. Its colossal dimensions make that its remains are still covered with a monumental character that recalls that of certain constructions of antiquity and that evoke its past ornamental exuberance through their details and vestiges. A thorough analysis of these, along with a comparative study to other contemporary and previous buildings, allows us to establish a hypothesis on its original shape that, at the same time, helps us to understand some of its functions and meanings. For this study of the North Hall, which had to be one of the most important spaces of the palace according to its size and situation, we have followed a similar methodological process to that applied in other previous works on the site, including a detailed survey, the study of traces still visible in the structures preserved, a comparative study with contemporary buildings and the analysis of graphic and textual sources.

Keywords: Sa'adí architecture, recording of standing walls, qubba, bahw.

Recibido: 21 noviembre 2013. Aceptado: 21 abril 2014.

Cómo citar este artículo / Citation

Almagro, A.: "El Salón Norte del Palacio al-Badi' de Marrakech: Estudio arqueológico e hipótesis sobre su forma original", Arqueología de la Arquitectura, 11: e016. doi: http://dx.doi.org/10.3989/arq.arqt.2014.003.

\section{Copyright}

(c) 2014 CSIC. Este es un artículo de acceso abierto distribuido bajo los términos de la licencia Creative Commons Attribution-Non Commercial (by-nc) Spain 3.0. 


\section{Introducción}

El palacio al-Badi' de Marrakech es seguramente uno de los conjuntos áulicos más imponentes del occidente islámico, no sólo por sus enormes proporciones fuera de lo habitual sino también por lo original de su estructura. Recientemente hemos dedicado un primer estudio a una de sus partes ${ }^{1}$ y con este nuevo artículo abordamos el análisis de otro de sus espacios más significativos.

Los restos que aún subsisten de este palacio están situados dentro de lo que fue la qasba sa'adí de Marrakech donde formaban parte del conjunto palatino renovado durante ese período sobre el mismo emplazamiento que ocupó la anterior qasba almohade ${ }^{2}$. Este palacio fue probablemente la más importante obra arquitectónica del sultán Ahmad al-Mansur al-Dehbhi ${ }^{3}$ que gobernó entre 1578 y 1603. Con esta suntuosa y monumental obra se propuso sin duda crear un marco arquitectónico que constituyera un respaldo a su política encaminada a sustentar su legitimidad y la construcción de una ideología imperial ${ }^{4}$.

La construcción del palacio se inició en diciembre de 1578, el mismo año en que ascendió al trono su promotor tras la batalla de al-Qasr al-Kebir, también conocida como de los Tres Reyes a causa de que en ella perdieron la vida los tres monarcas que allí combatieron: Abu Abadallah Muhammad II pretendiente al sultanato, su aliado D. Sebastián de Portugal y el sultán 'Abd alMalik, hermano de al-Mansur. La derrota de los dos primeros y la muerte de los tres proporcionaron a alMansur la ocasión de apropiarse no sólo del trono, sino de la gloria de la victoria que en verdad correspondía principalmente a su hermano fallecido. El sustancioso botín logrado de los pertrechos de los vencidos y los cuantiosos rescates que debieron pagar por su liberación muchos de los prisioneros capturados, proporcionaron fondos para el inicio de la construcción a los que se sumaron posteriormente los pingües beneficios que generaba la producción azucarera del reino y los beneficios de la campaña de conquista del Sudán, que permitió el control del comercio del oro proveniente de esta región. Su construcción se desarrolló hasta 1594, aunque en 1602, poco antes de la muerte de al-Mansur, aún seguían haciéndose obras.

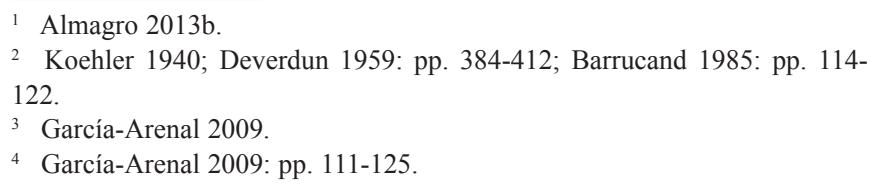

4 García-Arenal 2009: pp. 111-125.

En su política exterior Ahmad al-Mansur hubo de hacer frente a las presiones del imperio otomano, fuertemente asentado en los vecinos territorios de la actual Argelia, y a la realidad del fin de al-Ándalus con la presencia de potentes estados cristianos al otro lado del estrecho de Gibraltar. La caída de Granada, acaecida apenas un siglo antes, y el hecho de que muchos de sus habitantes habían emigrado al norte de África, le permitía sentirse legítimo heredero de su legado, al contar entre sus súbditos a una parte considerable de los antiguos pobladores del reino nazarí. Al-Mansur estaba bien informado de cuanto sucedía en la Península Ibérica, figurando entre sus planes, quizás más propagandísticos que reales, la reconquista de al-Ándalus 5 . El desaparecido reino nazarí y los edificios y palacios levantados por sus soberanos constituían para él un referente al que acudir en busca de formas y modelos que permitieran sustentar sus aspiraciones políticas y que sin duda sirvieron de inspiración para la construcción de su palacio.

Este fabuloso conjunto tuvo una vida efímera ya que fue destruido por el sultán alauí Muley Ismail (1672-1727) no sólo para llevarse sus materiales a Meknes, sino para eliminar cualquier construcción que pudiera rivalizar con los palacios que estaba construyendo en su nueva capital. Así lo confirman distintas fuentes, tanto árabes como occidentales ${ }^{6}$.

Al-Badi' era en realidad la parte pública del palacio del sultán, destinada a las grandes ceremonias de audiencia y a los festejos cortesanos entre los que cabe destacar las celebraciones del mawlid, que más que a conmemorar el nacimiento del Profeta parecían estar destinadas a la mayor gloria del propio sultán, que sin duda fue el principal objetivo buscado en la construcción de este conjunto.

Por sus proporciones descomunales, y considerado como célula diferenciada dentro del conjunto residencial al que pertenecía, se trata sin duda del edificio áulico más grande que conocemos en el mundo islámico occidental, con unas dimensiones de 155 x 130 m (Fig. 1). Su disposición, como es habitual en la arquitectura palatina andalusí, orbita en torno a un patio de 150 x 106 $\mathrm{m}$ en el que están presentes como verdaderos protagonistas junto a la arquitectura, el agua y la vegetación. En su perímetro se levantan crujías y pabellones que por el tamaño del conjunto adquieren dimensiones y aspecto que nada tienen que ver con las de otras construcciones

\footnotetext{
García-Arenal 2009: p. 116.

al-Ifrani 1889: p. 193; Estelle 1931.
} 


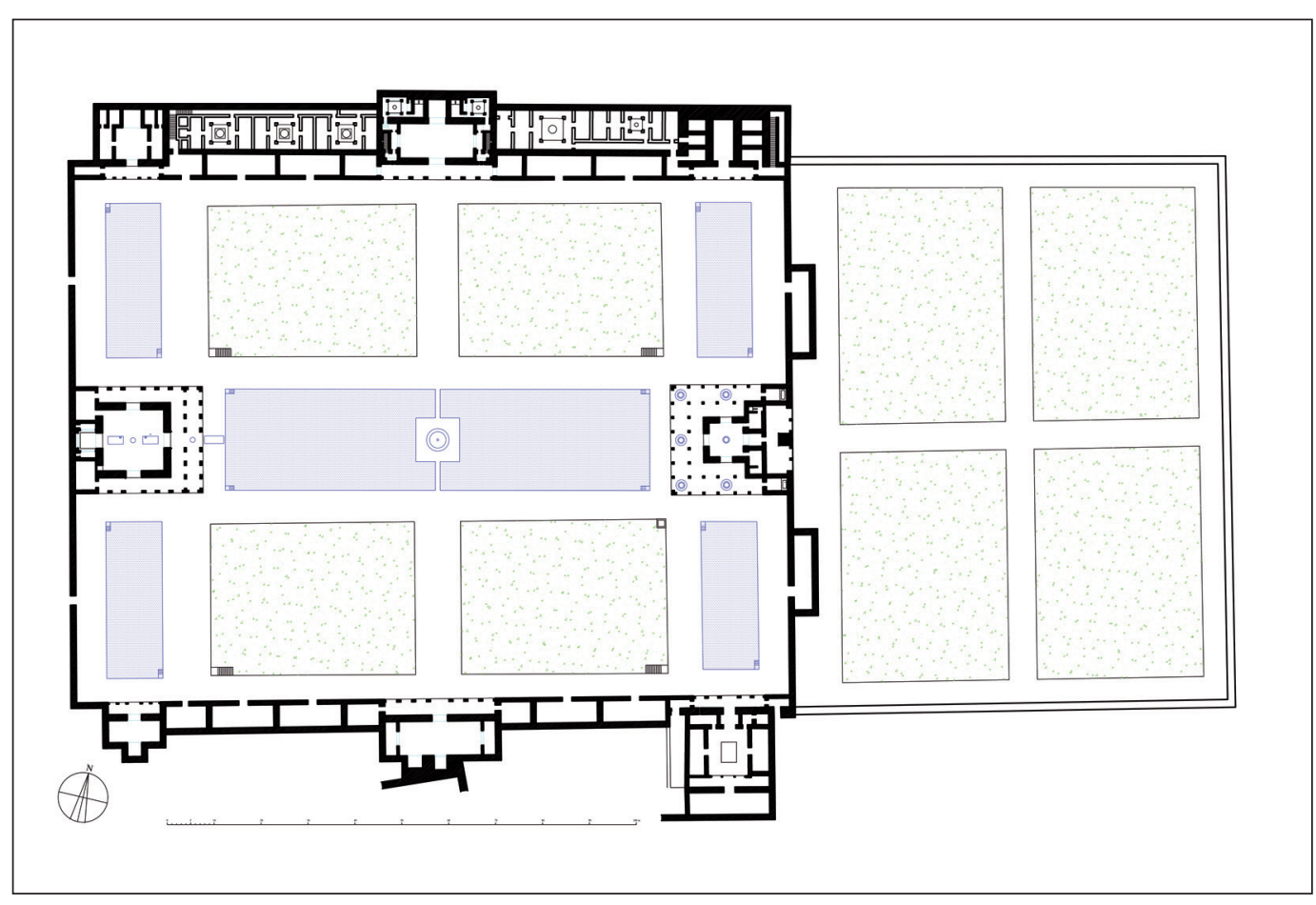

Figura 1. Planta General del palacio al-Badi' de Marrakech anteriores o posteriores, aún cuando como vamos a ver, los elementos que en él se integran y su ordenación son también reflejo de los modelos andalusíes, en los que sin duda su promotor buscaba dar continuidad como modo de legitimarse.

El centro del patio está ocupado por una gran alberca de 90 × $20 \mathrm{~m}$ dispuesta según la dirección del eje mayor, es decir Este-Oeste, y en cuyo centro hay una pequeña isla que parece albergó una fuente de doble taza según puede deducirse de documentos gráficos contemporáneos.

La alberca está rodeada por cuatro grandes áreas de vegetación de forma rectangular rehundidas más de dos metros respecto a los andenes por lo que la vegetación allí plantada apenas sobresaldría del nivel de los paseos que las rodean, facilitando de este modo la contemplación completa del conjunto sin interferencias visuales a la vez que se lograba una percepción de alfombra vegetal en una parte considerable de la superficie del patio ${ }^{7}$. La separación entre las zonas de jardín se hace mediante amplios andenes, que estuvieron solados con azulejos de colores, y que en la dirección longitudinal bordean también la alberca mientras en la transversal forman un a modo de crucero que queda interrumpido por la alberca, aunque estrechos puentecillos permitían cruzarla a través de la isla. En los cuatro ángulos del patio hay

\footnotetext{
Almagro-Vidal 2008: p. 254.
}

otras cuatro albercas que junto con la central rodean dos pabellones de los que hablaremos a continuación.

Seguramente los elementos más distintivos de este conjunto lo constituían los dos pabellones con forma de qubba que se levantaban en el centro de los lados menores del patio. Sólo en el del lado occidental nos han llegado en pie los muros de su estructura principal, aunque nada de sus elementos ornamentales ni de cubrición. Del pabellón oriental únicamente se conserva su cimentación. Conocemos los nombres dados a ambos edificios: la Qubba al-Jamsiniyya y la Qubba al-Dehbhiyya $^{8}$. La primera era la del lado occidental y su nombre aludiría a su dimensión de 50 codos, algo más de 25 metros. El nombre de la segunda, la del lado oriental, haría referencia a los dorados de su decoración o incluso al sobrenombre del propio sultán, al-Dehbhi. En algunas descripciones también se cita esta qubba con el nombre de al-Zuŷaziyya ${ }^{9}$ o de cristal.

En todo el perímetro del patio existían otras dependencias de muy diversa índole y de entre ellas al-Fištali nos describe la existencia de otras dos qubbas, aunque más bien se trata de salones, situados uno en frente del otro en los laterales del palacio ${ }^{10}$. Analizaremos el situado en el centro del lado norte, que a juzgar por sus

\footnotetext{
Deverdun 1959: p. 397

al-Fistali 1964: p. 171.

10 al-Fistali 1964: p. 171
} 


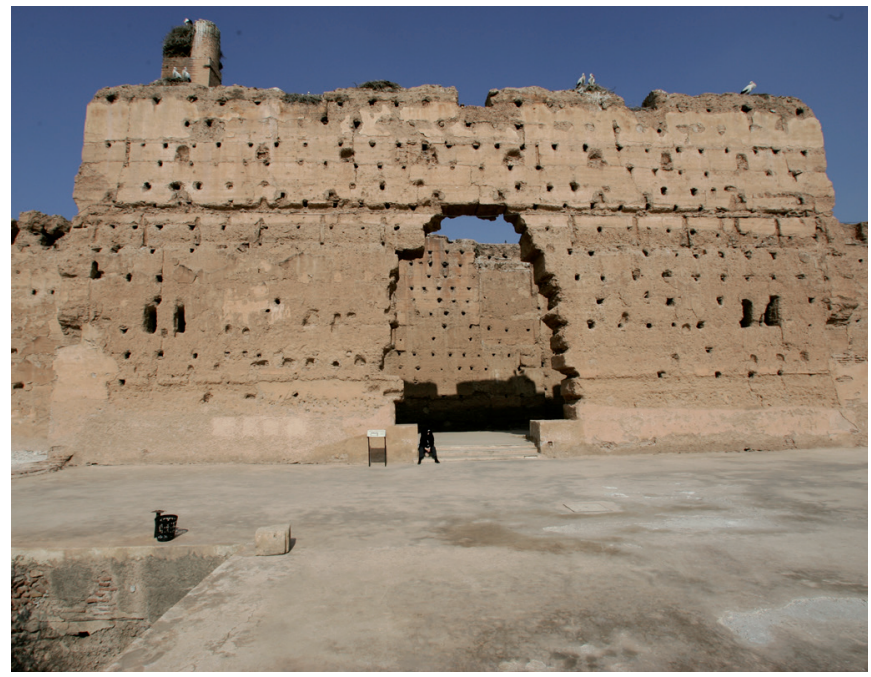

Figura 2. Vista del Salón Norte en 2005.

dimensiones y ubicación pudo ser uno de los espacios protagonistas de todo el conjunto (Fig. 2). Desgraciadamente, el salón del lado sur fue objeto de una restauración hace algunos años que hace imposible cualquier estudio que permita conocer su forma original. El pórtico construido en su frente y la cubrición realizada mediante bóvedas en ese salón meridional son, en todo caso, estructuras que nada tienen que ver con las formas originales pero que han acarreado la pérdida de información que habría sido muy valiosa para una correcta intervención en él. En el salón del lado norte pudimos hacer una toma de datos antes de la última intervención restauradora llevada a cabo en el palacio, que aunque no tan agresiva como la antes mencionada, también ha supuesto la ocultación o destrucción de información valiosa y la comisión de algunos errores graves como haber construido un arco de ladrillo a modo de puerta en el muro del lado este del espacio actual, dentro de un hueco que allí había, sin duda abierto cuando, después del expolio del palacio, este espacio se dedicó a una actividad fabril. Bastaría haber visto la conocida información gráfica de la época o el plano dibujado por los excavadores del palacio de la época del protectorado para percatarse de que en ese punto nunca hubo una puerta. Nuestro estudio lo corrobora. Por otro lado, la existencia del hueco no suponía ningún peligro para la estabilidad de los muros. Algo parecido cabe decir respecto al arco de entrada al salón, también reconstruido con ladrillo hasta una altura que interfiere con el arrocabe que corría a todo lo largo del muro, tanto por el exterior como por el interior.

\section{Metodología}

El proceso seguido para este estudio ha sido el habitual en nuestros trabajos ${ }^{11}$. Lo iniciamos con la toma de datos de fotografías realizada con una cámara Canon EOS 1Ds de 22 Mpix. de resolución y objetivos de $28 \mathrm{~mm}$ y $20 \mathrm{~mm}$ convenientemente calibrada para uso fotogramétrico. Se hizo un croquis de la planta y se tomaron medidas para su dibujo con un metro-láser Leica Disto.

A continuación se abordó la realización de los dibujos de estado actual. Para ello se orientó un bloque de 20 fotografías que cubrían todos los paramentos de la sala, tanto exteriores como interiores, y que conformaban además 8 pares estereoscópicos, usando el programa Orthoware ${ }^{12}$. Para la orientación absoluta se utilizaron algunas de las medidas tomadas manualmente y la referencia de un plano horizontal, para lo que aprovechamos la huella de la parte superior del zócalo de alicatado. Con este sistema evitamos tener que usar un taquímetro $\mathrm{u}$ otro instrumento semejante ${ }^{13}$. La precisión lograda, con errores de alrededor de $3 \mathrm{~cm}$, la consideramos suficiente para los objetivos de este trabajo pues resultan prácticamente inapreciables a la escala en que se reproducen los planos en la publicación. Por este procedimiento obtuvimos coordenadas tridimensionales de 66 puntos que fueron utilizados como puntos de control para la orientación de los pares estereoscópicos con el programa PoivilliersF ${ }^{14}$. Por medio de la restitución realizada con el auxilio de la visión estereoscópica se obtuvieron los dibujos tridimensionales de la planta y de las cinco caras visibles del edificio (Fig. 3-8) que al integrarse en un solo dibujo nos permitió obtener un modelo 3D que refleja su estado en el momento en que se realizó la toma de datos (Fig. 10). Este procedimiento, que venimos utilizando en muchos de nuestros trabajos, permite realizar los levantamientos con un tiempo muy breve de permanencia en el sitio y con instrumentos de coste muy reducido y fácilmente transportables a cualquier lugar. Esta documentación se ha complementado con la realización de ortofotos y de un modelo 3D texturizado con el uso del programa Photoscan (Fig. 9 y archivo pdf adjunto).

Sobre la base de la planimetría obtenida iniciamos el estudio de las propuestas de reconstrucción que basamos en las huellas que se conservan en el monumento y

\footnotetext{
11 Almagro et al. 2008.

12 Desarrollado por Metria Digital. http://www.orthoware.es/cas/index.asp.

13 Almagro 2013a: pp. 15-16.

14 Desarrollado por Yves Egels del IGN de Francia (Almagro 2011).
} 


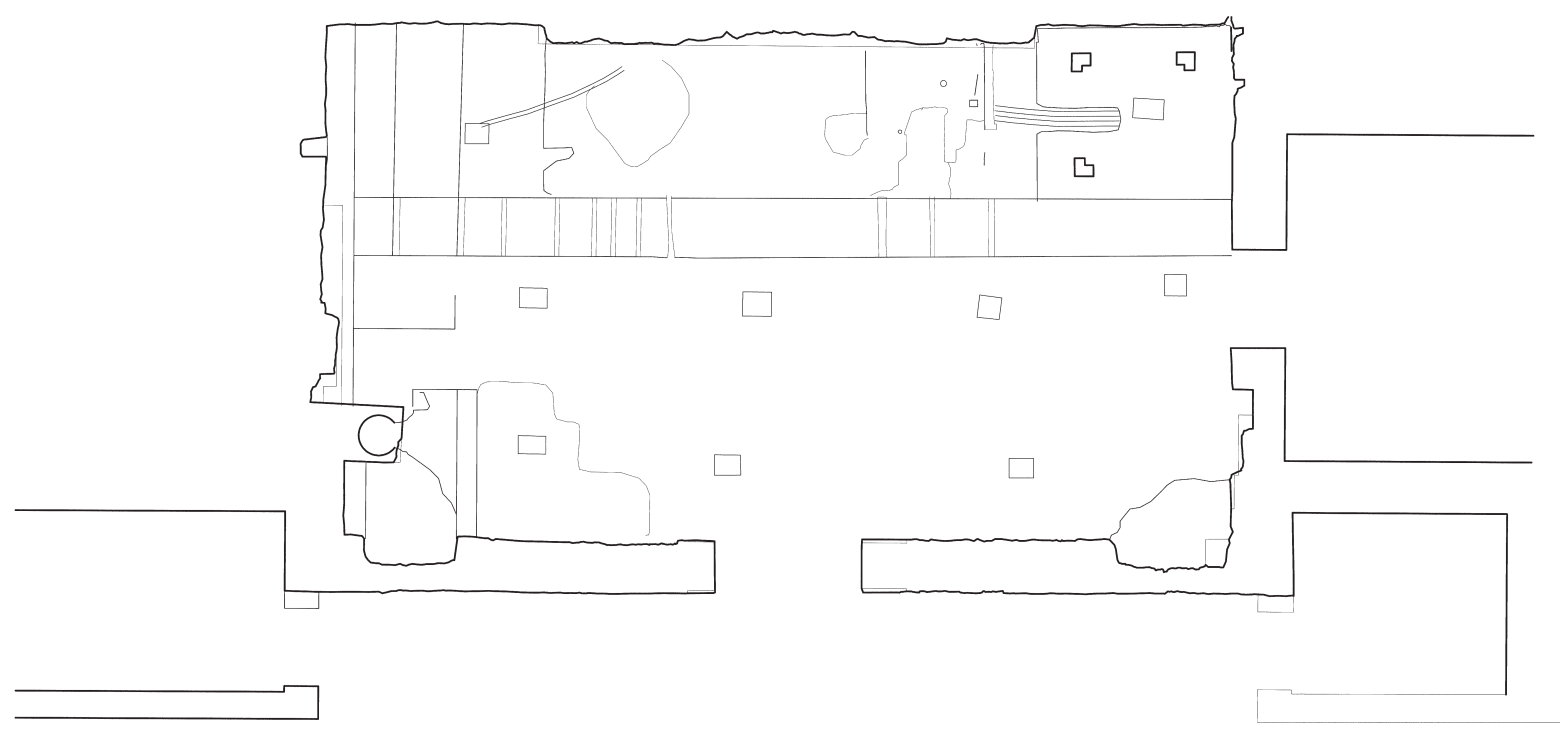

Figura 3. Planta del Salón Norte en 2005

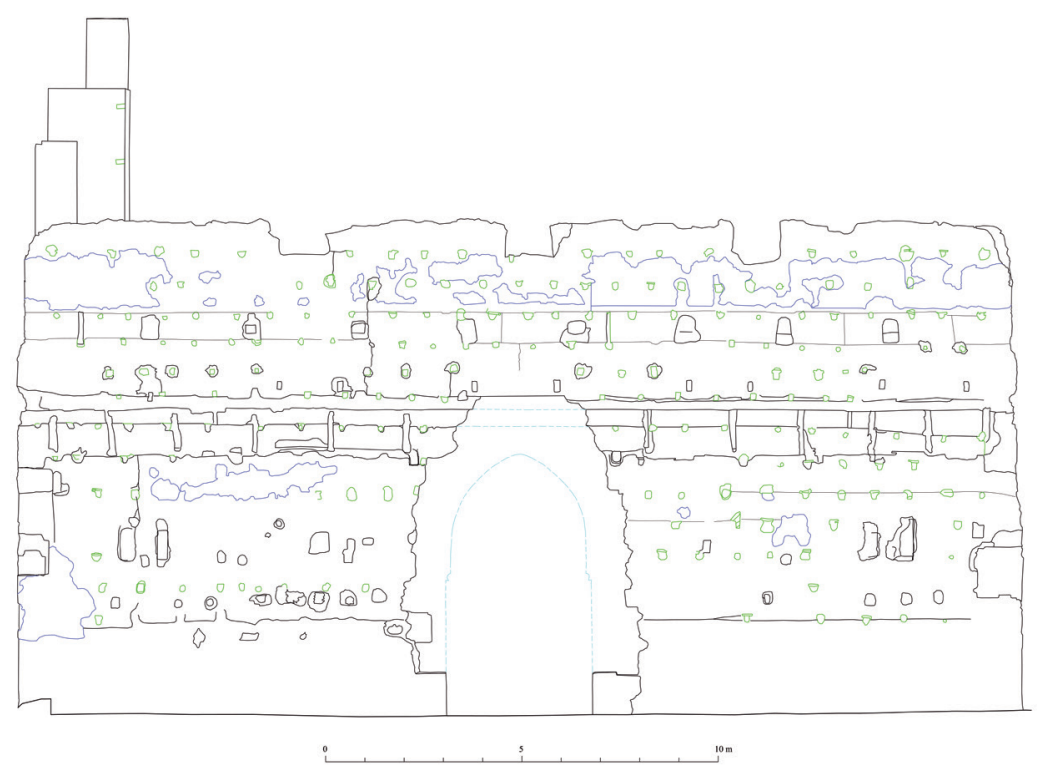

Figura 4. Alzado exterior actual del Salón Norte 


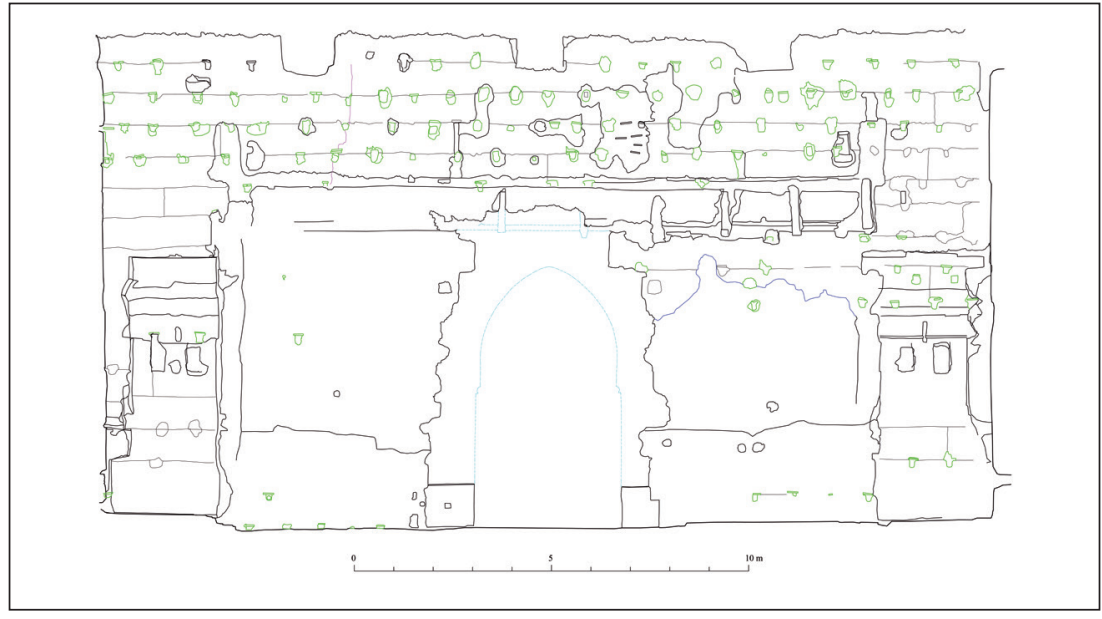

Figura 5. Alzado interno del lado sur del Salón Norte

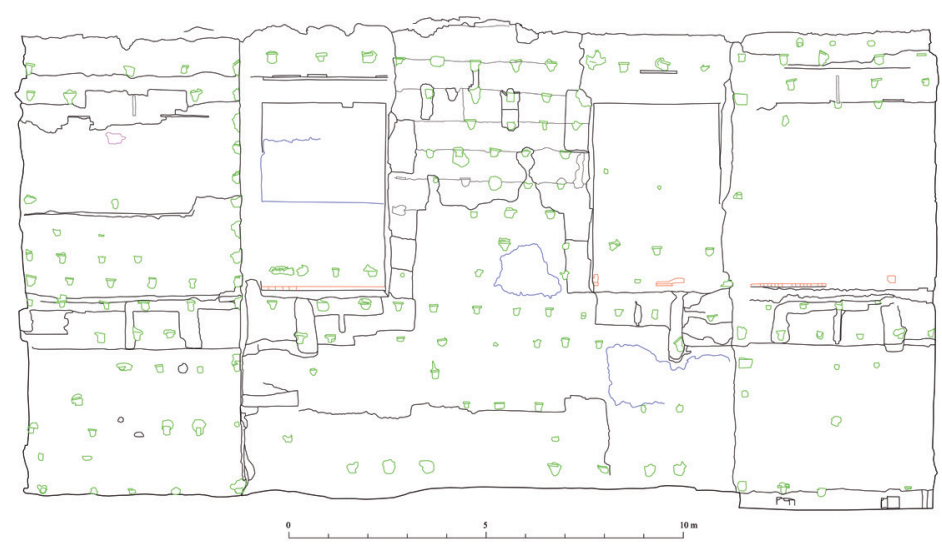

Figura 6. Alzado interno del lado norte del Salón Norte
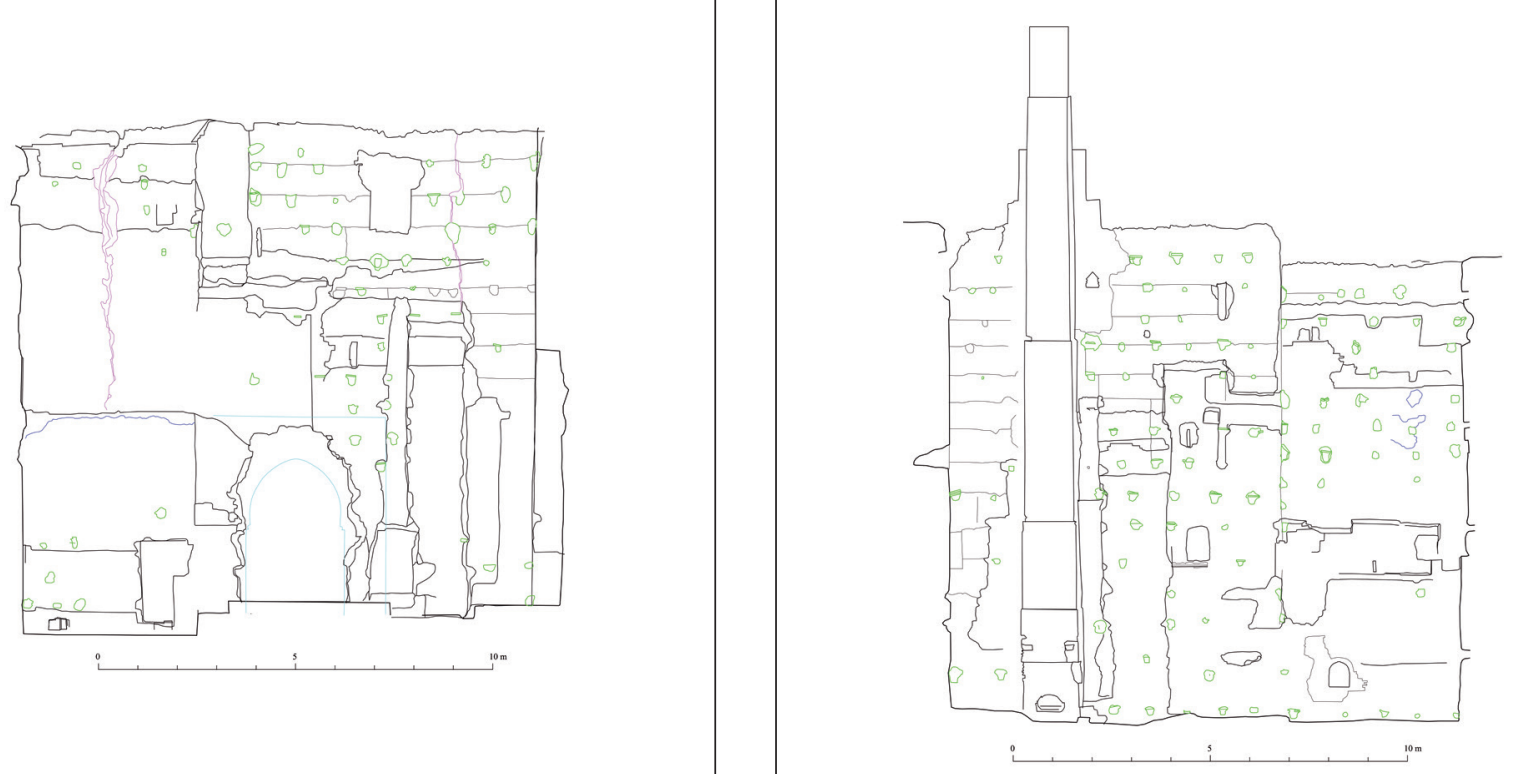

Figura 7. Alzado interno del lado este del Salón Norte

Figura 8. Alzado interno del lado oeste del Salón Norte 

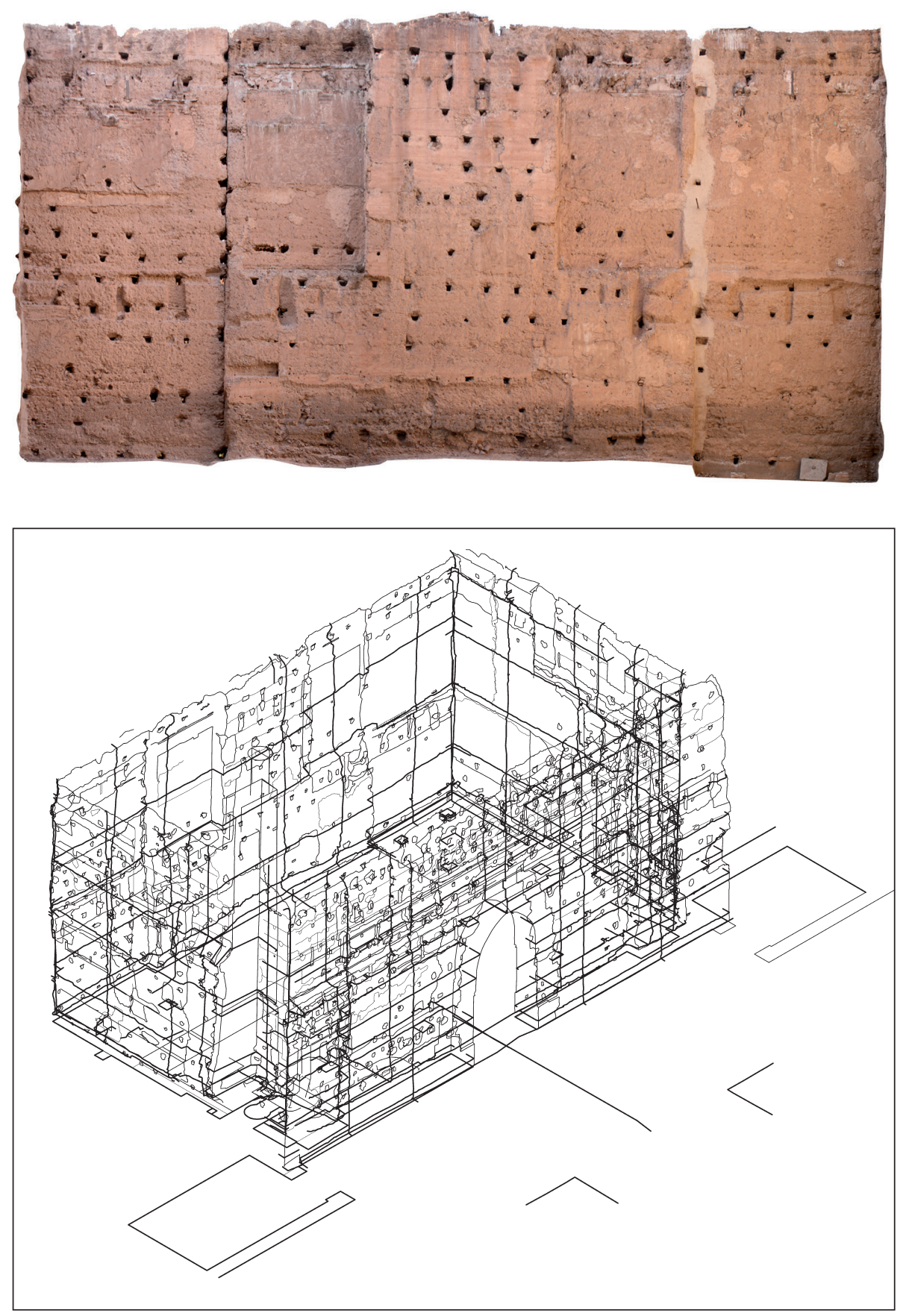

Figura 9. Fotoplano del lado norte del Salón Norte

Figura 10. Modelo 3D del Salón Norte

en el estudio comparativo con otros edificios semejantes, lo mismo contemporáneos como de períodos anteriores. En este caso, tal proceso se ha realizado tanto mediante la inspección ocular in situ, como por observación de los pares estereoscópicos que permiten en muchos caso ver con mayor comodidad y detalle muchas de estas huellas. Para el estudio comparativo se ha recurrido a realizar otros levantamientos parciales de algunos de los edificios que presentan semejanzas. El estudio de fuentes, tanto escritas como gráficas, ayudó a completar la información. Con estos datos se inició el proceso de propuesta que se ha realizado primeramente mediante dibujos en 2D de plantas, alzados y secciones.

\section{EI Salón Norte}

En el centro del lado norte del patio existe en la actualidad un gran espacio rectangular conformado por muros de tapia de notable altura, aunque sin cubrición alguna (Fig. 11). En realidad, este gran espacio de 23.00 


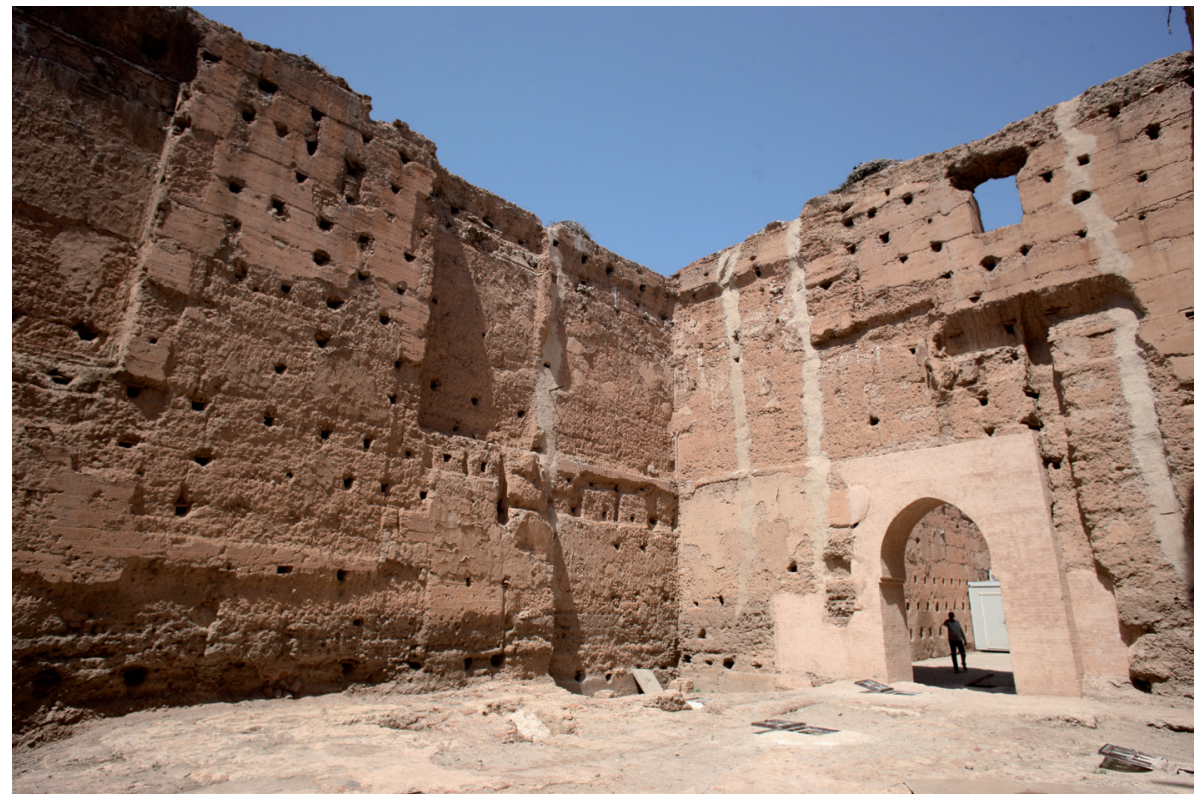

Figura 11. Vista interior actual del Salón Norte x $12.90 \mathrm{~m}$ es el resultado de la demolición de diversos muros internos que lo dividían en diversas salas y habitaciones, quedando de ellos visibles algunas huellas tanto en los paramentos como en el suelo. Según la descripción del palacio realizada por el visir y poeta al-Fištali, contemporáneo de al-Mansur, y aunque sea con todas las reservas posibles, podemos identificar el salón que aquí se levantaba como la Qubbat al-Nasr de acuerdo con los datos que este autor aporta ${ }^{15}$.

Para establecer la hipótesis sobre la forma y apariencia original de este salón disponemos, además de la información que nos proporcionan las estructuras conservadas, de dos testimonios gráficos contemporáneos al edificio que nos aportan datos de enorme utilidad. El primero de ellos es el dibujo realizado por el fraile trinitario Antonio de Conçeyçao, adjunto a un informe remitido a Felipe II sobre el martirio sufrido por siete jóvenes cristianos en 1585 por orden de Ahmad al-Mansur, y que se conserva en la biblioteca de El Escorial (Fig. 12) ${ }^{16}$. El dibujo, que cuenta con el interés de estar realizado a color, nos ofrece una descripción de la qasba sa'adí llena de ingenuas representaciones pero de fácil interpretación gracias al realismo con que se muestran. Para lo que más nos interesa del salón norte, podemos destacar los siguientes detalles:

\footnotetext{
15 En esta interpretación coincidimos en los aspectos básicos con la realizada por Mouline (2009: pp. 139-148). No obstante, tanto a este autor como a Deverdun o Barrucand les ha faltado un análisis arqueológico detallado del monumento.

16 Biblioteca de El Escorial, nº sign. d.III.27; Koehler 1940.
}

a. El salón presenta en su frente al patio un pórtico formados por arcos sostenidos sobre columnas, con un vano central de mayor tamaño con arco de lambrequines. A diferencia de lo que ocurre con los pabellones de los lados este y oeste, aquí el dibujo resulta mucho más confuso y parece no representar con verosimilitud la realidad.

b. Sobre el pórtico no se dibuja tejado sino que parece que el paramento seguía en su vertical hasta el alero general del pabellón. Esto resulta totalmente contrario a la realidad que nos muestran las estructuras existentes. Seguramente se trata de una simplificación poco realista.

c. Por encima del pórtico se representa el paramento con un aparejo de grandes sillares, seguramente fingido sobre la obra de tapia, tratamiento que también presentan las qubbas oriental y occidental. En este caso no se representa sebka sobre los arcos del pórtico.

d. El cuerpo del salón se cubre con un tejado de pabellón a cuatro aguas. El tejado se representa con tejas verdes.

e. Lo más confuso del dibujo es que este pabellón aparece como si tuviera pórticos en tres de sus lados, lo que resulta a todas luces imposible ya que de acuerdo con las estructuras que han sobrevivido no se adentraba hacia el centro del patio como los pabellones de los lados este y oeste, sino que su frente quedaba enrasado con el de todas las construcciones del lado norte.

La otra imagen con la que contamos corresponde a un plano esquemático pero bastante bien proporcionado y detallado, dibujado en 1623 por el erudito holandés Jacob 


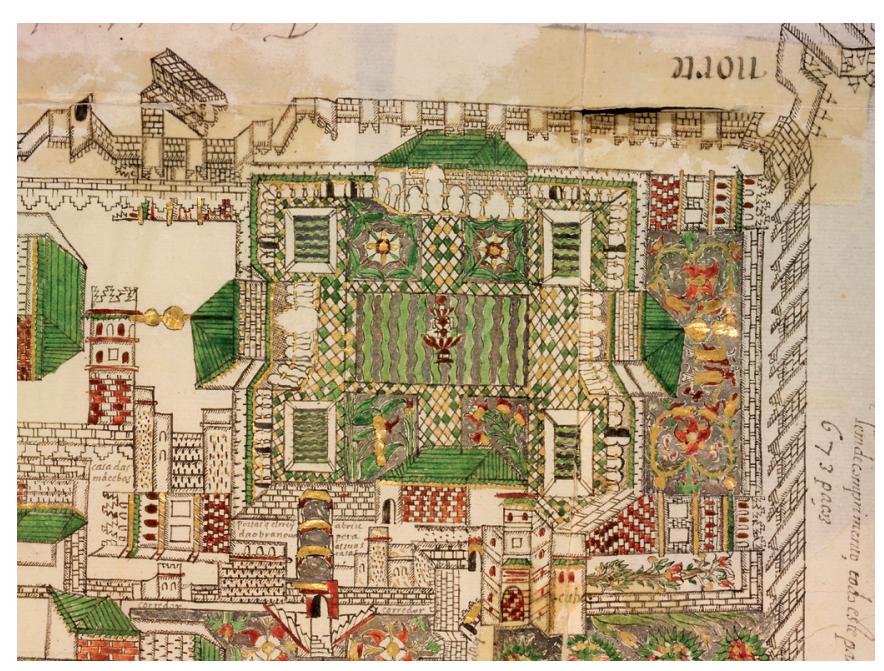

Figura 12. Dibujo del palacio al-Badi' conservado en la Biblioteca de El Escorial con el Salón Norte representado en el centro de la parte superior. (c) Patrimonio Nacional.

van Gool, también conocido como Jacobus Golius, y publicado por John Windus en 1725 (Fig. 13) ${ }^{17}$. También en este caso nos interesan los detalles siguientes:

1. El pórtico frontal es de una sola crujía con siete arcos y un vano mayor en el centro que coincide con la puerta del salón, tal y como también aparece en el dibujo de El Escorial.

2. Aunque con algunos errores, se representan con bastante exactitud puertas y arcos así como las fuentes y albercas del interior de las salas y los pórticos, corroborando y completando en parte la información que da el propio suelo actual del palacio.

3. En lo que respecta a este salón del lado norte vemos que en realidad era un espacio con planta de $\mathrm{T}$ invertida, muy característica de la arquitectura residencial del norte de África. Aparece bien representado un pórtico de siete vanos, con el central de mayor tamaño y con una fuente en su frente. La parte transversal del salón en T se dibuja con alhanías en sus extremos, a través de las cuales se accede a dos patios ubicados a ambos lados del espacio que forma el palo vertical de la T, y a los que a su vez se abren otras pequeñas habitaciones. Aunque ya veremos que las proporciones de estas habitaciones tal y como aparecen en este dibujo difieren bastante de la realidad, este croquis nos proporciona unos indicios de enorme utilidad para determinar cómo era la distribución interior del pabellón.

\footnotetext{
17 Windus 1725: p. 222, reproducido en Meunier 1957: fig. 1. Aunque el plano aparece rotulado como Palacio Real de Fez, no cabe duda de que se trata de un error.
}

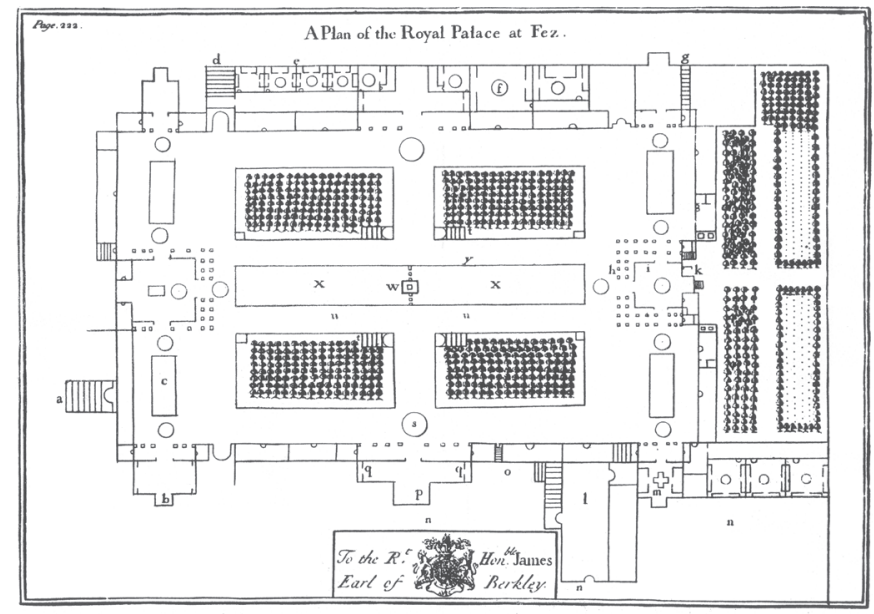

Figura 13. Planta del palacio al-Badi dibujada por Jacob Gool en 1623 (reproducida de Meunier 1957) con el Salón Norte en el centro de la parte superior

Con toda esta información y la minuciosa observación de numerosos detalles conservados en los paramentos del edificio que aún subsisten, hemos podido plantear la hipótesis representada en los planos y dibujos que presentamos y que nos permiten describir la forma original de los distintos espacios y estructuras que quedaban integrados dentro de él.

Gran parte de los cuerpos de edificación del lado norte, y entre otros este salón que nos ocupa, se construyó sobre una infraestructura que dio lugar a una serie de habitaciones de sótanos que aunque se usarían como almacenes, su verdadera función fue la de proporcionar una plataforma a un nivel adecuado sobre la que construir las dependencias del palacio salvando de este modo el desnivel natural ${ }^{18}$.

El interior del edificio estaba ocupado mayoritariamente por un gran salón de planta en $\mathrm{T}$ invertida, con alhanías en los extremos del brazo horizontal, y por dos pequeños patios con habitaciones anejas que se adosaban al espacio dispuesto según el trazo vertical de la T (Fig. 14). En las zonas inmediatas a los patios hubo unas estancias en planta alta a las que se accedería mediante escaleras que suponemos dispuestas en los extremos laterales. Nada de lo que venimos de describir se aprecia a simple vista cuando se penetra en el espacio actual, aunque son numerosas las huellas que aparecen en los paramentos, pero en las que se mezclan trazas de la estructura original con huecos y aditamentos debidos

\footnotetext{
18 Todas las lucernas que hoy se ven en el suelo que ventilan e iluminan esos sótanos son de apertura moderna. Algunas han dañado elementos de interés como los restos del pavimento de alicatado.
} 


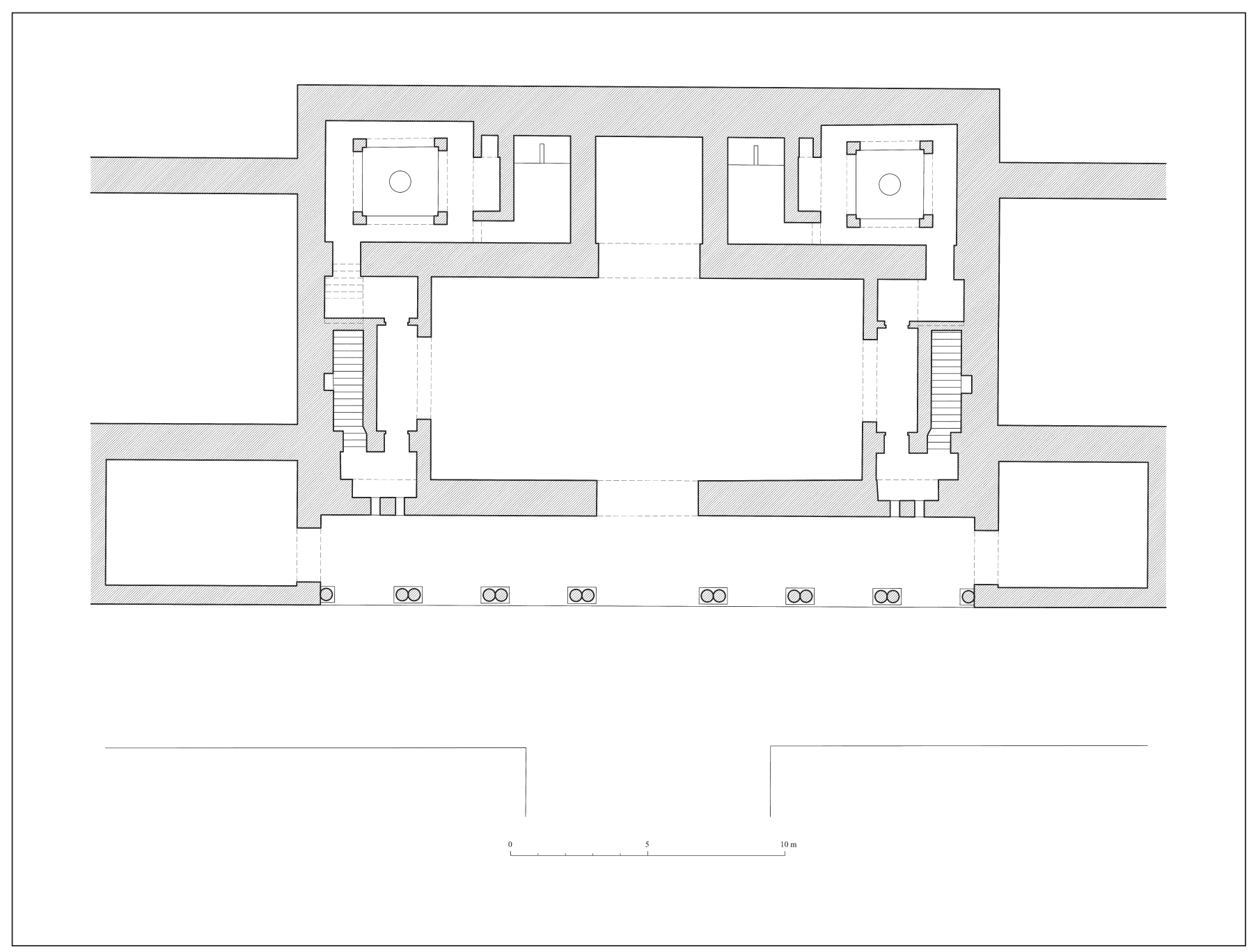

Figura 14. Planta baja hipotética del Salón Norte o Qubba al-Nasr del palacio al-Badi'

a la reutilización posterior del espacio y a trabajos de restauración recientemente realizados y a nuestro entender muy poco afortunados ${ }^{19}$.

La zona de más fácil análisis es la correspondiente al frente sur en donde se levantaba el pórtico (Figs. 2 y 4). Aquí, la sencillez de la estructura, la semejanza con otros casos ya estudiados en el palacio y la claridad de las huellas visibles en el paramento hacen fácil la lectura de la disposición original.

\footnotetext{
19 Merece destacarse la presencia de una chimenea adosada al lado oeste junto al extremo sur, que sin duda corresponde a un uso tardío de carácter industrial de este espacio y que seguramente provocaría la desaparición de las divisiones internas si es que éstas no fueron eliminadas durante el expolio del palacio. Según referencias (Aimel 1918: p. 62; Deverdun 1959: p. 537), parece que existió dentro de sus ruinas una industria de fundición de metales establecida por el sultán Muley Hassan (1873-1894) quizás dedicada a la producción de armas, por lo que cabe relacionar esta chimenea con alguna fundición usada en su fabricación.
}

El análisis de los paramentos y la experiencia y conocimiento de las pautas ornamentales y métodos constructivos usados en la arquitectura andalusí ha permitido identificar las huellas que los distintos materiales y sistemas decorativos han dejado. Así, en la parte baja de los muros se aprecia un ligero picado de la superficie del paramento para facilitar la adherencia del mortero de agarre de los zócalos de alicatado. A una altura de aproximadamente $2.30 \mathrm{~m}$ el paramento vuelve a ser liso pues el yeso de la decoración labrada no tenía dificultades de adherencia y agarre. A 6.50 $\mathrm{m}$ de altura, aparecen los huecos dejados por una serie de rollizos verticales que se empotraron en la masa de la obra de tapia cada $1.80 \mathrm{~m}$ aproximadamente y que servían para fijar sobre ellos los tableros que conformaban el arrocabe de madera labrada y policromada.

Por encima de la huella del arrocabe se aprecia a $7.75 \mathrm{~m}$ del suelo una roza longitudinal en que se apoyaba 
el techo del pórtico, cuyas vigas debían ser de reducida escuadría o incluso puede que estuviera formado por simples tableros ataujerados con decoración de lazo clavada sobre paneles de madera, solución que resulta lógica ya que dicho techo no tenía ninguna función portante y el ancho del pórtico era escaso.

De hecho, $1.95 \mathrm{~m}$ más arriba encontramos los mechinales de ocho vigas que serían los pares que soportaban la cubierta. Es de notar que en la zona del paramento entre el techo del pórtico y la parte alta de los pares la fábrica de tapia se nos aparece totalmente desnuda, sin enlucido alguno, mientras que por encima y por debajo quedan distintos restos de enlucidos lo que prueba que esta zona correspondía al camaranchón que había entre el techo y el tejado del pórtico. En el borde superior del muro, muy deteriorado e irregular por efectos del expolio y la acción de la intemperie, aún se aprecia la existencia de tres huecos que pudieron corresponder a otras tantas ventanas. Es de suponer que los muros se rematarían con el correspondiente alero de canecillos de madera que quedaría anclado mediante un remate de fábrica de ladrillo que se asentaría sobre la obra de tapia y que hemos de presumir expoliado al igual que otros elementos hechos de igual modo.

De esta forma quedan perfectamente definidas todas las alturas de los diversos paños decorativos externos que resultan muy similares a las que encontramos en el pabellón occidental ${ }^{20}$, por lo que podemos presumir que las columnas y arcos de los pórticos de ambas construcciones eran muy semejantes. Basándonos en ello hemos establecido la propuesta de reconstrucción (Fig. 15).

El pórtico tenía a ambos lados dos habitaciones con entrada desde los extremos, cuya función nos resulta desconocida aunque pudieran relacionarse con espacios que se enumeran en la descripción coetánea que analizaremos más adelante.

Por el interior, los distintos paramentos nos ofrecen información bastante detallada con muchos datos fundamentales. En el lado sur resultan visibles tanto la huella del zócalo de alicatado como la de un amplio arrocabe que nos permite conocer el nivel del arranque del techo de la zona del salón correspondiente a la parte horizontal de la T (Fig. 5). La ausencia de este elemento en el centro del paramento norte que corresponde al extremo de brazo vertical de dicha $\mathrm{T}$ nos permite asegurar que ese espacio tuvo una solución distinta. El hecho de que por encima de esta huella del arrocabe no se vean me-

\footnotetext{
20 Almagro 2013b: pp. 10-11.
}

chinales de grandes vigas nos induce a pensar que esta sala no contó con techo de armadura sino que posiblemente se cubriría con un techo ataujerado ${ }^{21}$ semejante al que existe, por ejemplo, en el salón de Comares de la Alhambra $^{22}$. La sección dibujada a partir de estos datos nos muestra que debía quedar un gran espacio a modo de camaranchón, entre el techo de la sala y la estructura que soportaría el tejado y al que darían luz y ventilación las ventanas que hemos visto en la parte superior de la fachada (Fig. 16). De hecho, por encima de la huella del arrocabe la superficie de la fábrica de tapia aparece sin rastro alguno de enlucido o tratamiento, lo que indicaría que quedaba a la vista en una zona no visible desde el salón. Como se aprecia en la impronta dejada en el muro, el arrocabe no llegaba a los extremos del actual espacio y además se ven con bastante claridad las huellas de los muros que delimitaban por el este y el oeste el salón y que coinciden con el final del arrocabe, podemos determinar con precisión cuál era la dimensión de la sala en esa dirección. Para definir su anchura debemos fijarnos en la existencia de un cimiento que recorre en la misma dirección el centro del espacio actual y que sin duda corresponde al muro que lo dividía originalmente en dos crujías. La crujía frontal estaba pues ocupada por una sala alargada dotada de dos alhanías o nichos con arcos en los extremos según se desprende del plano de Gool. Pero además veremos que también debían estar en los extremos de esta crujía las escaleras de subida a las habitaciones altas existentes en la otra.

Las huellas visibles en el centro del muro norte correspondientes al espacio del brazo vertical de la $\mathrm{T}$ (Figs. 6 y 9) nos permiten conocer su anchura y, relacionándola con el ancho de la crujía septentrional, suponer que se trataba de una habitación de planta cuadrada, comunicada con la sala rectangular mediante un amplio arco que ocuparía casi todo su lado sur, sobre todo si presumimos que tenía la misma anchura que el arco de entrada al salón. Por los enlucidos que han quedado en el centro del muro norte parece que este espacio de la crujía más septentrional se cubría con un techo que debía tener una altura algo menor que el de la otra zona (Fig. 17). Como la planta de este espacio según nuestra hipótesis debió ser cuadrada, podemos pensar en un techo también ataujerado con forma de cúpula o con más

\footnotetext{
21 Techo conformado por tableros de madera sobre los que se van clavando las piezas para formar la decoración de lazo sin formar parte de una estructura apeinazada y portante. Por ello, estos techos no son nunca estructurales sino simplemente decorativos (Nuere 1989: pp. 143, 154).

22 Cabanelas 1988
} 


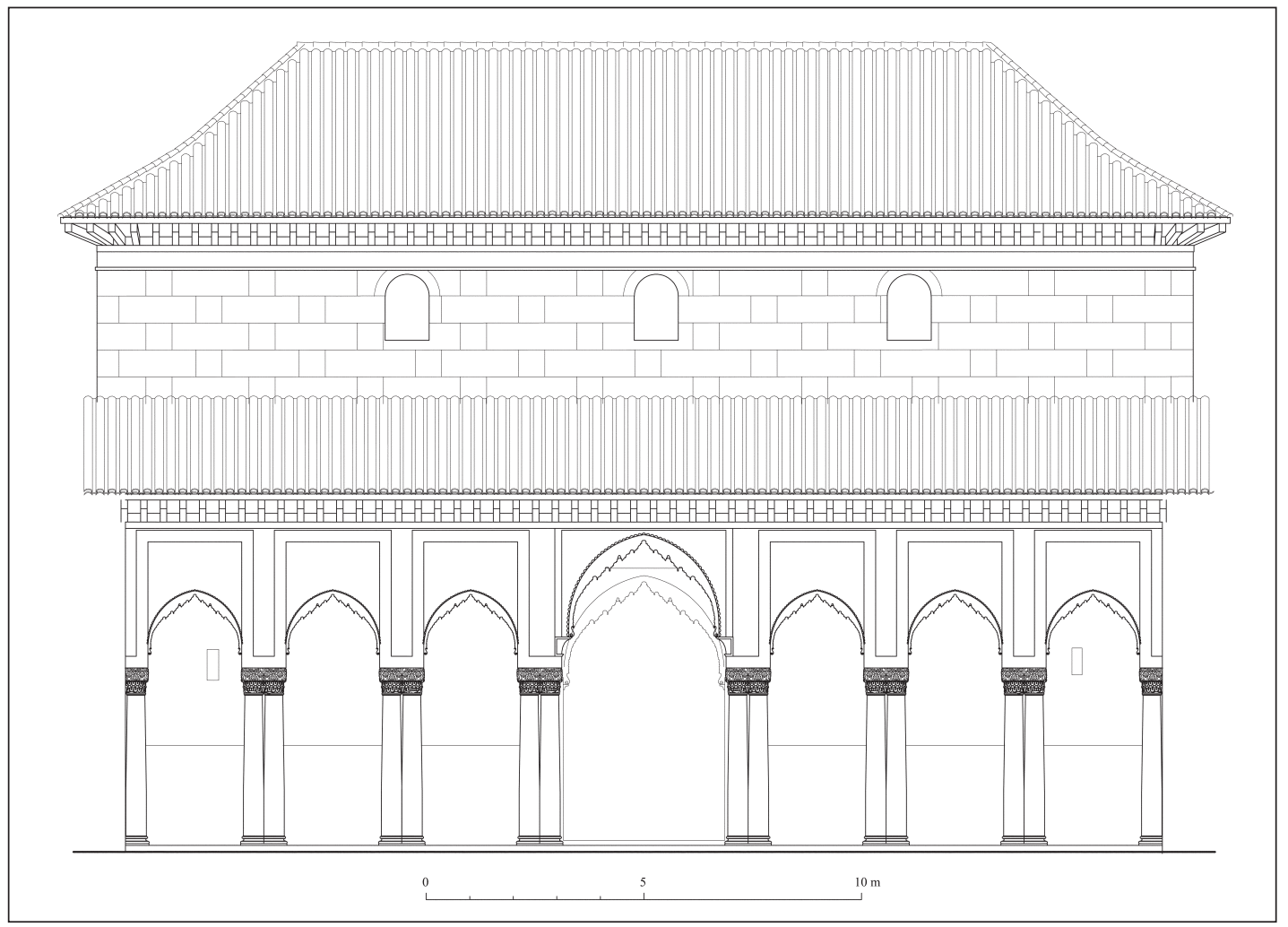

Figura 15. Alzado exterior hipotético del Salón Norte o Qubba alNasr del palacio al-Badi

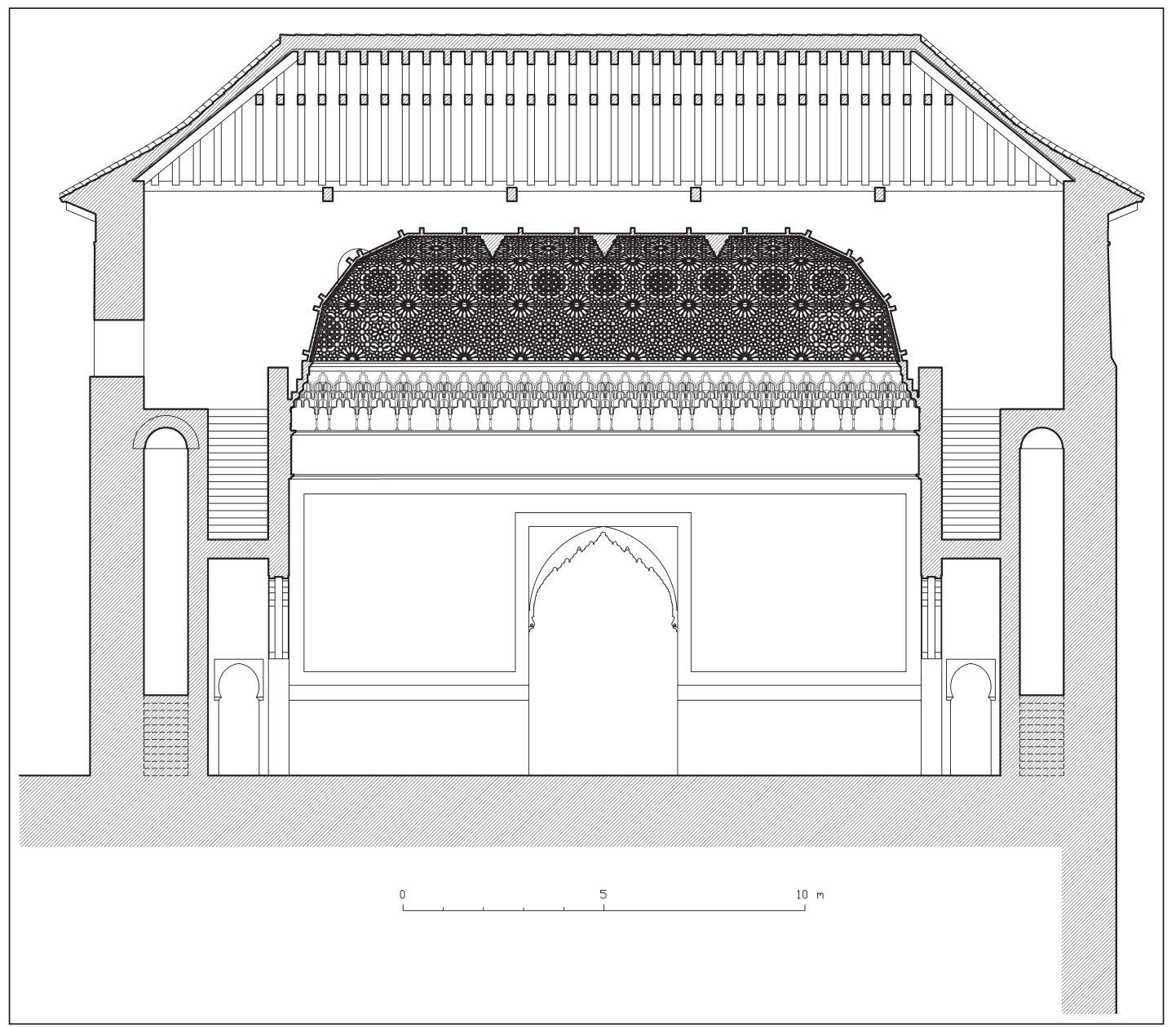




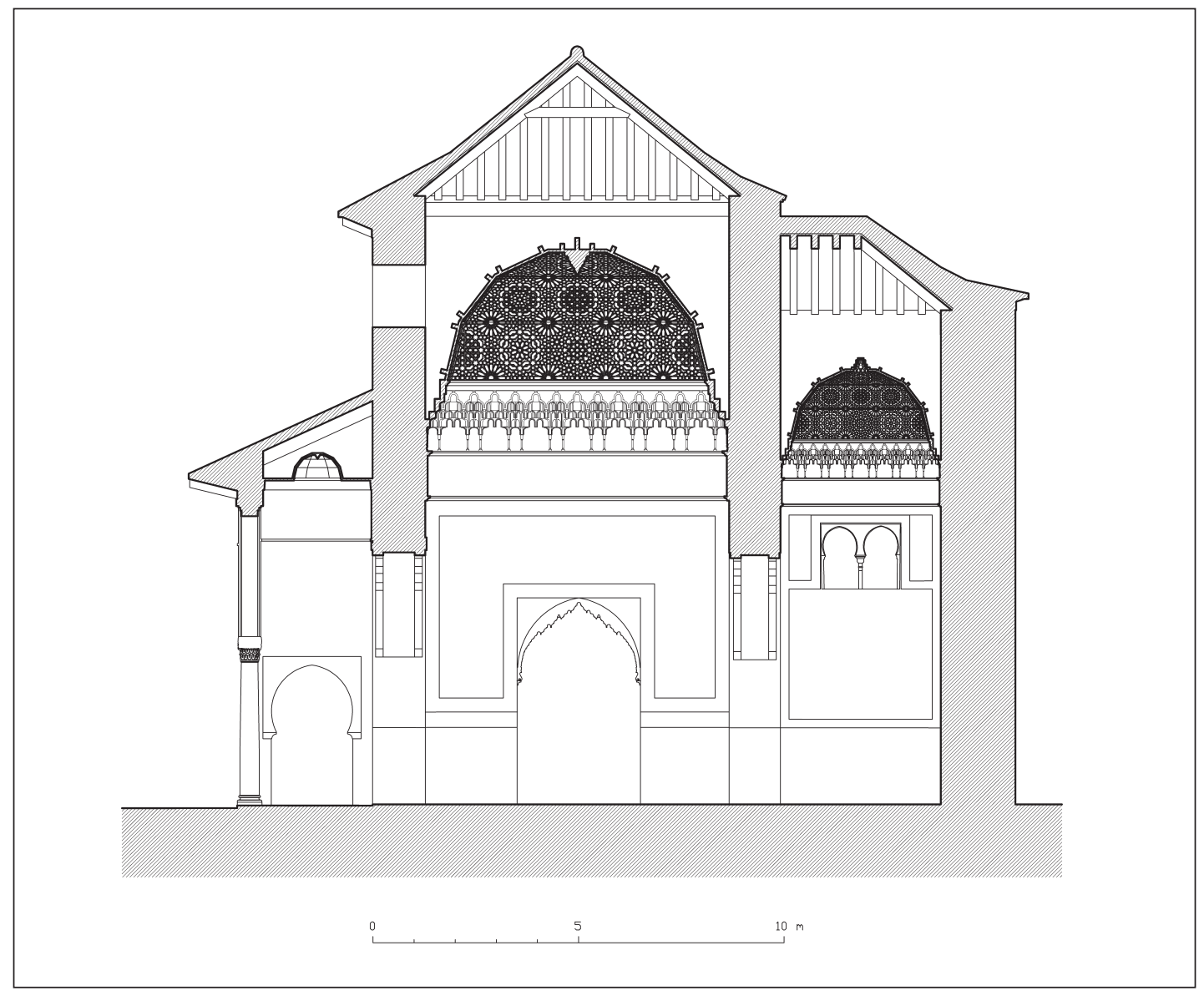

Figura 17. Sección hipotética por el eje central del Salón Norte

seguridad, un techo de planta cuadrada de cinco paños ${ }^{23}$. Este espacio, con forma de pequeña qubba, tuvo que funcionar como presidencia del salón con una solución muy parecida a la que se da en la qubba del lado occidental del patio y que creemos también estuvo presente en la oriental ${ }^{24}$.

Vemos cómo las dimensiones y forma del espacio principal quedan adecuadamente definidas gracias a los documentos gráficos y a las huellas que han pervivido de los elementos desaparecidos. Algo más complejo resulta descifrar la forma original de los espacios satélites. El plano de Gool nos indica que en las zonas que resultaban entre los brazos de la T había dos patios. En el área correspondiente al patio oriental quedaba en 2005

\footnotetext{
23 Al no existir en este caso ninguna huella de cuadrales o vigas diagonales, no cabe suponer la presencia de una estructura ochavada como la que hubo en el pabellón occidental (Almagro 2013b: pp. 11, 20). Para nuestra hipótesis hemos pensado en una solución similar a la del salón de Comares de la Alhambra (Cabanelas 1988).

24 Almagro 2013b: p. 9. Con menos vistosidad, también en el salón de Comares de la Alhambra se da una disposición semejante pues la epigrafía nos muestra que el pequeño espacio correspondiente al ventanal central del lado norte fue el lugar destinado al sultán (Puerta 2011: p. 126).
}

el arranque de tres pilares con forma de $\mathrm{L}^{25}$ lo que permite reconstruir su planta (Figs. 14 y 18). Estos patios los podemos imaginar muy semejantes a los existentes en las zonas de los dormitorios de los estudiantes de la madraza Ben Yusef de Marrakech ${ }^{26}$ (Fig. 19). Por el plano de Gool sabemos que se entraba a ellos desde la alhanía del salón rectangular, aunque hemos de suponer que el ingeniero holandés simplificó la solución en el dibujo, ya que tampoco representa la escalera de subida a la planta superior. En el patio oriental se conservan dos tuberías que debieron funcionar una como acometida de agua y otra como desagüe de la fuente que Gool dibuja en el centro del patio. En el patio occidental no hay restos visibles de conductos.

En estas zonas, a juzgar por las huellas existentes en los muros, sabemos que hubo un piso alto conservándose las improntas de los arrocabes y alfarjes y algunos azulejos del zócalo de la planta alta, lo que nos permite dibujar con bastante seguridad una sección por esta

\footnotetext{
25 Cuando visitamos de nuevo el monumento en 2012, el pilar más distante del muro norte había desaparecido.

26 Triki y Dovifat 1999: pp. 103-117, 184.
} 


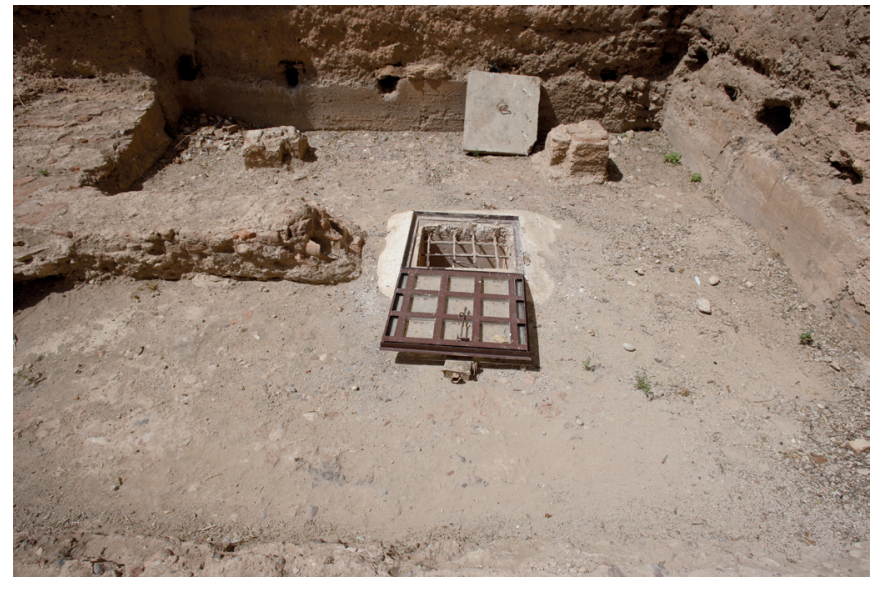

Figura 18. El patio del lado oriental con los arranques de dos pilares en $L$ y las canalizaciones de la fuente. El hueco abierto en el centro para ventilar los sótanos es moderno

parte (Fig. 20). De lo que no cabe duda es de que en la planta superior, entre el patio y la qubba sólo hubo una habitación en cada lado tal y como muestran las huellas del muro norte, mucho mejor conservado en la parte alta que en la baja, donde la humedad de capilaridad ha producido grandes estragos en su masa (Fig. 21).

Concretamente tenemos en la pared del lado norte y en ambos lados, los huecos de los zoquetes sobre los que se clavó el arrocabe de las galerías inferiores de los patios y la roza correspondiente al apoyo del alfarje.
También se ve la huella del arrocabe del piso superior (Figs. 6 y 9). En la zona de las habitaciones del piso alto, la pared sufre un rebaje para hacerlas más anchas y las vigas de los forjados debían ir en paralelo al paramento norte apoyándose en los muros hoy desaparecidos. Sin embargo aquí si ha quedado la huella de la banda inferior de los paños de alicatado incluso con algún trozo de azulejo (Fig. 22), y también queda algún trozo más de alicatado en la zona correspondiente a la galería alta del patio del lado oriental (Fig. 23).

Más dudas presenta la distribución en la planta baja. Según Gool la zona entre el patio y la qubba estaba ocupada por dos pequeños cuartos (Fig. 13), aunque las improntas en el muro norte y las huellas que quedan en el suelo resultan algo confusas para fijar con precisión sus dimensiones. El grueso del muro que separaba la qubba de las letrinas se puede deducir con bastante seguridad de las huellas del muro, aunque no está tan clara la situación del otro muro paralelo. Dentro del espacio que suponemos letrina del lado oriental hay una arqueta de registro cuadrada y dos tubos cerámicos que salen verticalmente (Fig. 3). Uno más grueso, situado más cerca del muro norte que pudo ser el desagüe de la letrina y otro más delgado que abastecería de agua una pileta y que hemos de considerar que subía empotrado dentro del muro antes mencionado. Si el desagüe estaba en el centro de la habitación podemos deducir aproximadamente la situación

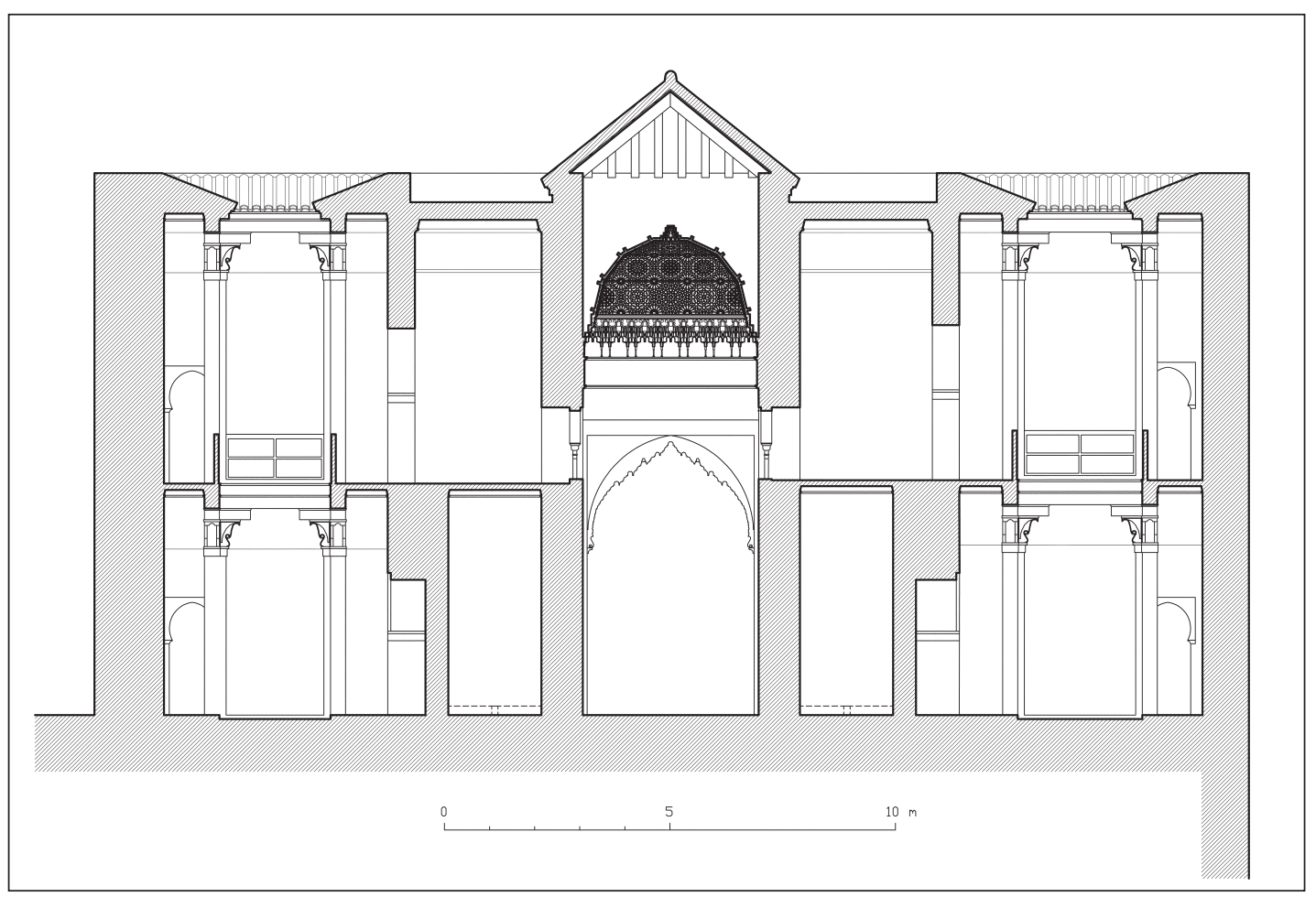

Figura 19. Sección hipotética por la segunda crujía del Salón Norte 


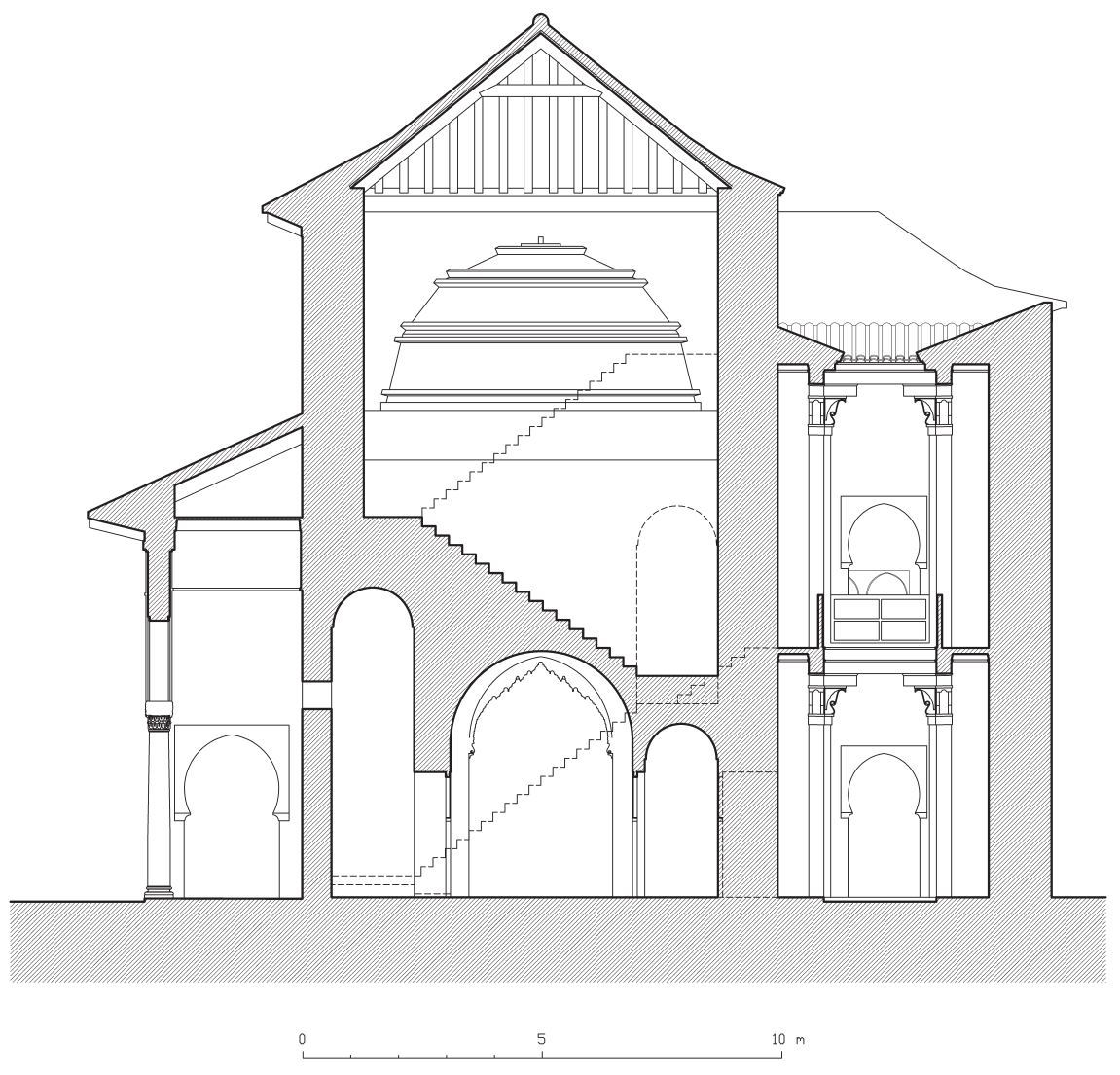

Figura 20. Sección hipotética del Salón Norte por la segunda crujía

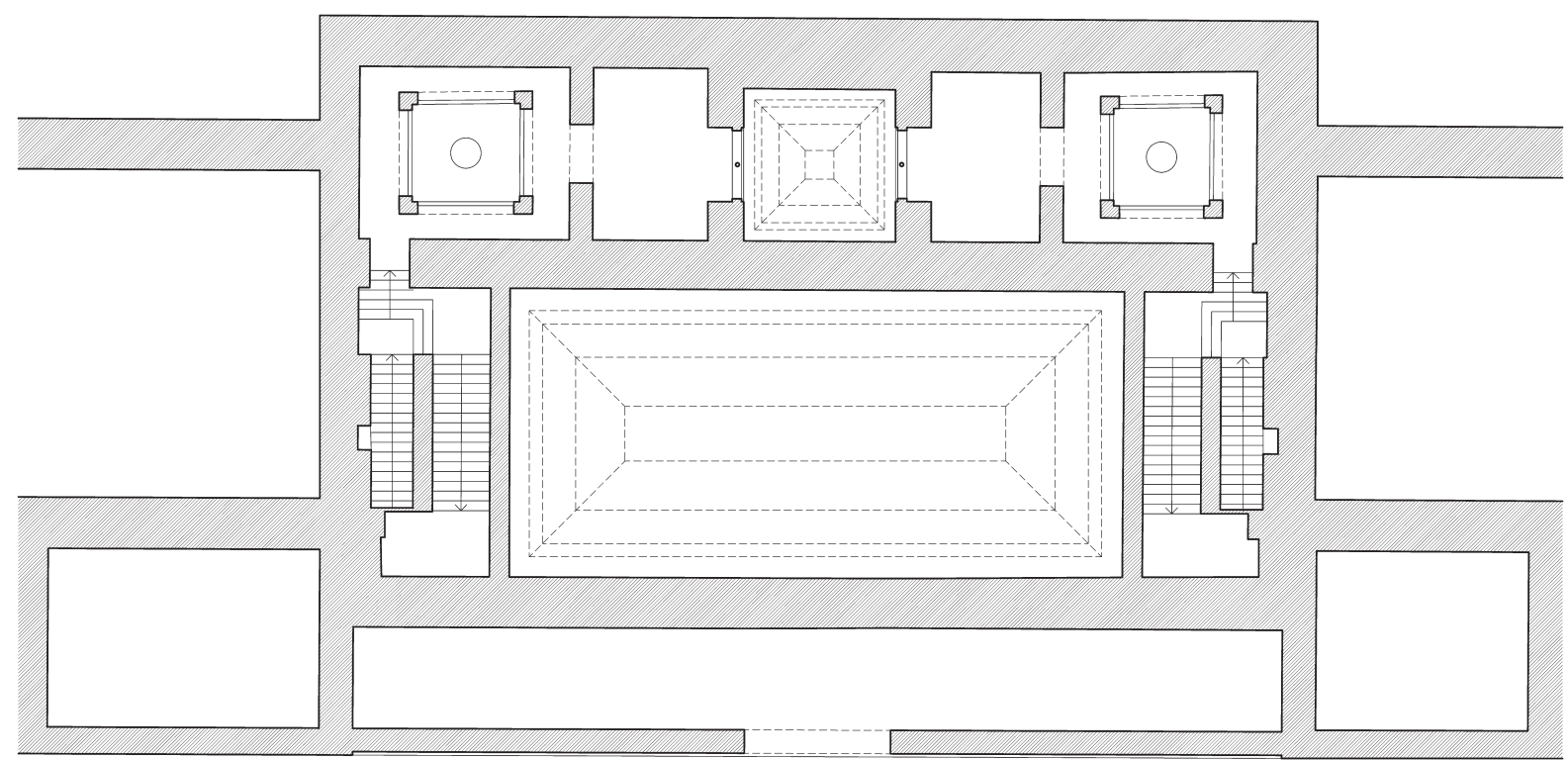




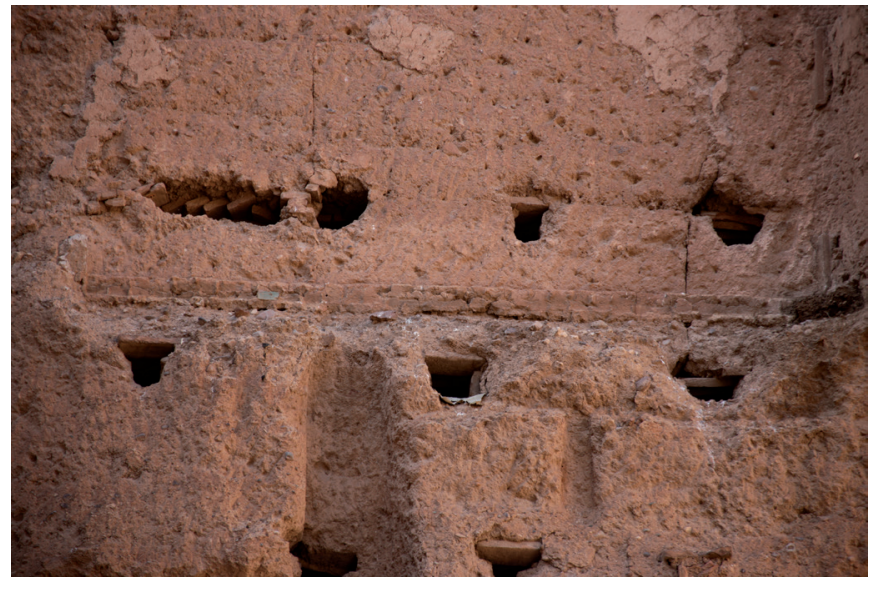

Figura 22. Restos de alicatado de la galería alta del patio oriental

del otro muro, que coincide con una huella visible en el suelo actual. En el lado occidental también existe una conducción de tubos cerámicos que correspondería al desagüe de la letrina y que se dirige hacia el centro del patio de ese lado. Las letrinas tenían forma de pasillo en recodo con puerta en la esquina del patio. Gool dibuja una a modo de alhanía o nicho en el lado de éste contiguo a la letrina tal como hemos dibujado en la solución que proponemos, sin que dispongamos de mayores indicios para ello. Estos nichos pudieron estar destinados a espacios de reposo o quizás a alojar a los servidores que vigilaban y limpiaban los retretes.

Imaginamos que las habitaciones superiores contaron con alguna ventana o abertura que permitiera ver lo que sucedía en el salón de forma discreta. Estas habitaciones pudieron por tanto estar destinadas tanto al reposo como a ser ocupadas por personas que desearan ver discretamente las ceremonias y recepciones que ocurrían en el salón sin ser vistas, como por ejemplo, a las mujeres del sultán.

La otra cuestión de solución más compleja es la disposición de las escaleras por las que se subía a ese piso alto. Que éstas existieron no nos cabe duda, aunque Gool no las dibuje, pues resultaban imprescindibles para acceder al mismo. Y además tuvieron que ser dos ya que la presencia del bahw en el centro del edificio impedía que existiera comunicación entre las plantas altas de ambos lados.

De las escaleras tenemos algunos datos suministrados por los paramentos de los lados este y oeste. En el lado occidental se conserva la cenefa inferior, la que estaba en contacto con el pavimento, de un zócalo de alicatado que se encuentra a una altura inferior a la de los que se conservan en el muro norte correspondientes al piso alto

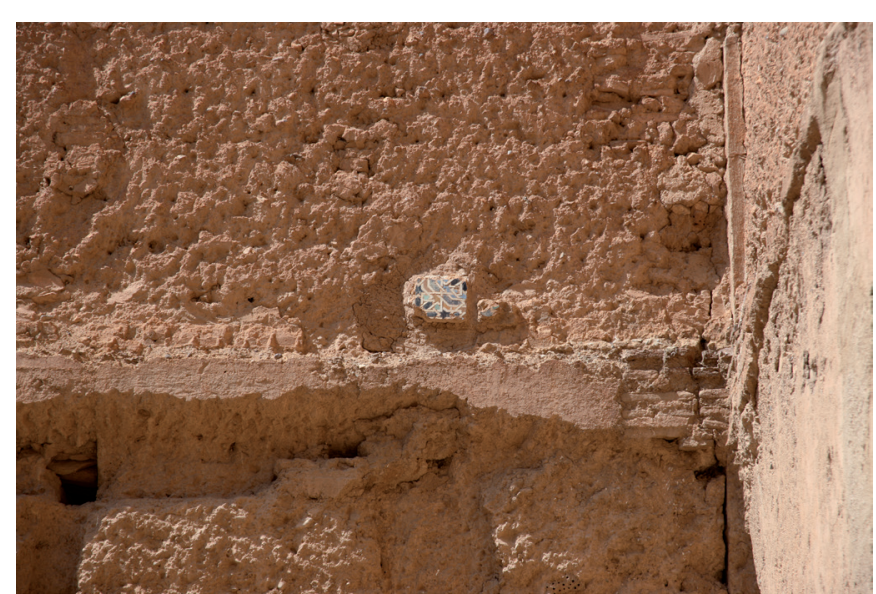

Figura 23. Huella del zócalo de azulejos de la habitación alta del lado occidental

(Figs. 8 y 24). Esto nos hace suponer que ese zócalo podría corresponder a un descansillo de la escalera. En base a esto hemos dibujado una hipótesis que creemos bastante plausible. Las escaleras arrancarían de los ángulos meridionales del actual edificio, desde unas habitaciones en parte horadadas en el muro meridional a las que se accedería también a través de la alhanías por puertas enfrentadas a las de acceso a los patios. Cada una de estas habitaciones tenía dos ventanitas abiertas al pórtico del edificio (Figs. 14 y 20). Las escaleras subirían entre dos muros con un solo tramo hasta los descansillos antes mencionados situados aproximadamente en el centro de los actuales paramentos oriental y occidental. En estos descansillos las escaleras se debían dividir tomando dos direcciones (Fig. 21). Una seguiría la misma que en el tramo inferior para alcanzar las galerías altas de los patios. La otra seguiría subiendo en paralelo al tramo primero, por encima de las alhanías del salón, pero con dirección contraria, para acceder a los camaranchones y posiblemente a alguna terraza que hubiera en parte del edificio. Esta hipótesis estaría avalada por la existencia del apoyo de unas bóvedas escalonadas que se aprecia en el paramento oriental, horadado en la masa de tapia del muro y que cubrirían el primer tramo de la escalera (Figs. 7, 11 y 25). Desgraciadamente en el lado occidental los indicios son más confusos al haberse construido la chimenea de uso industrial (Fig. 26) cuando el edificio ya se había destruido, lo mismo que en el lado oriental, no ha quedado huella del descansillo de la escalera por haberse abierto un gran hueco de paso para comunicar la sala resultante tras las demoliciones interiores con el espacio contiguo que al parecer también sufrió un proceso semejante.

En lo que respecta a la decoración que pudieron tener estos espacios debemos guiarnos igualmente por las huellas dejadas tras el expolio. Como en el pórtico, 


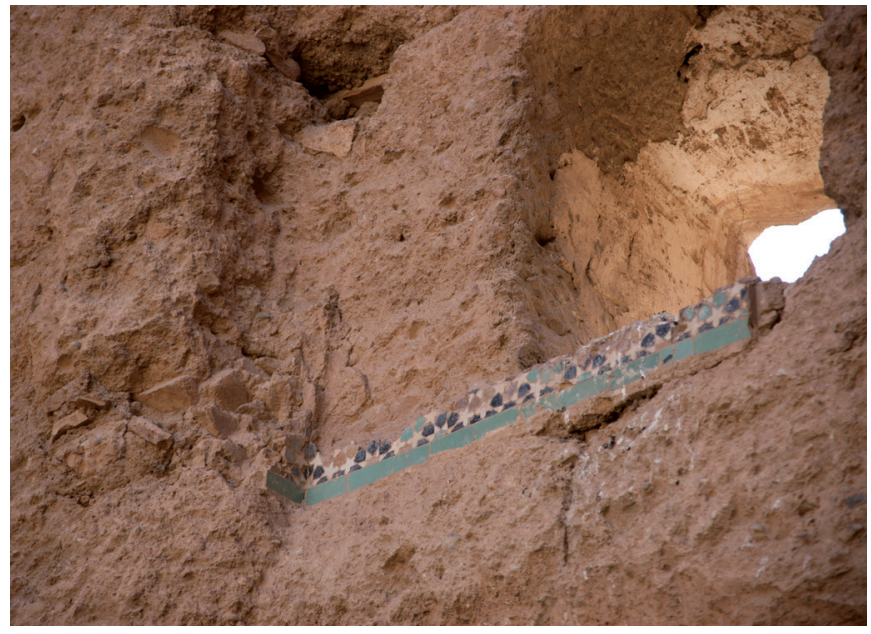

Figura 24. Restos de alicatado en el descansillo de la escalera occidental

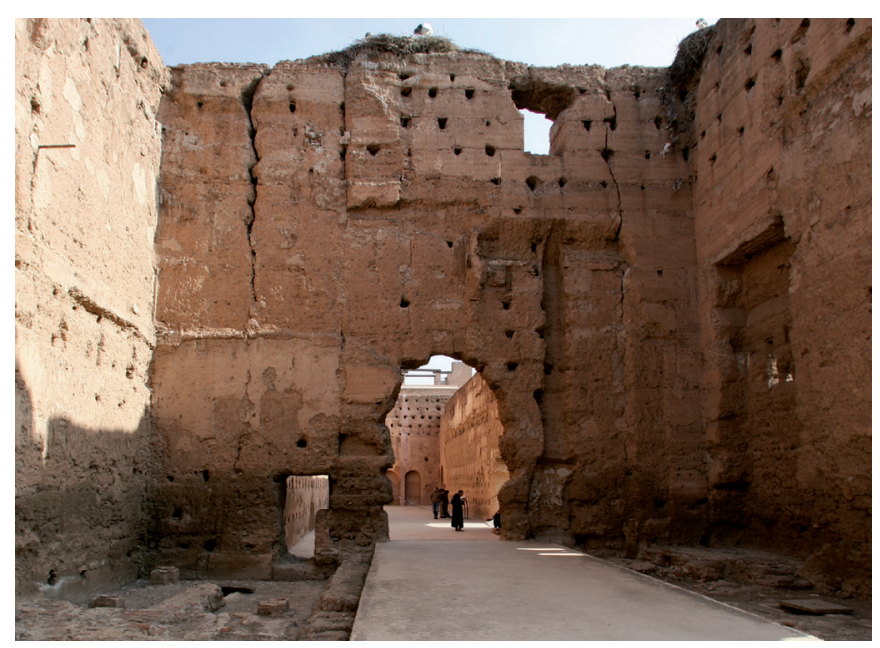

Figura 25. Vista del lado oriental del Salón Norte mostrando los cajeados para el apoyo de las bóvedas que cubrían la escalera

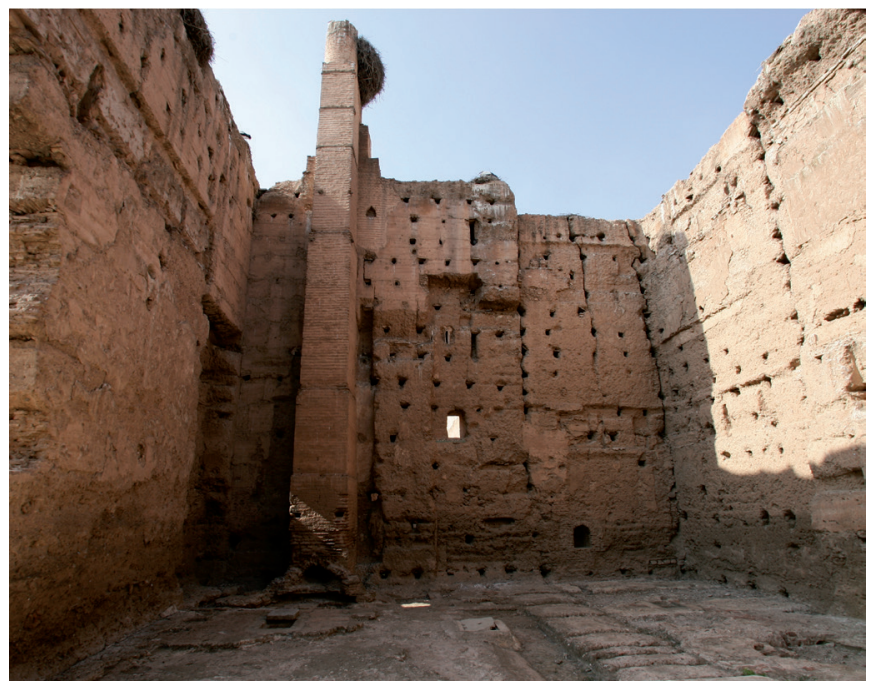

Figura 26. Vista del lado occidental del Salón Norte con la chimenea de su reutilización industrial

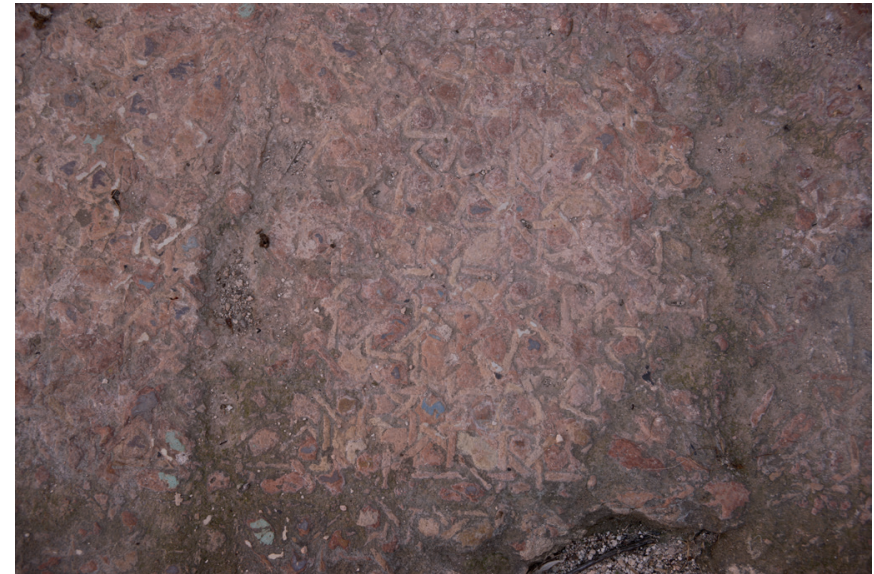

Figura 27. Restos del alicatado del pavimento del Salón Norte conservados en su ángulo sureste

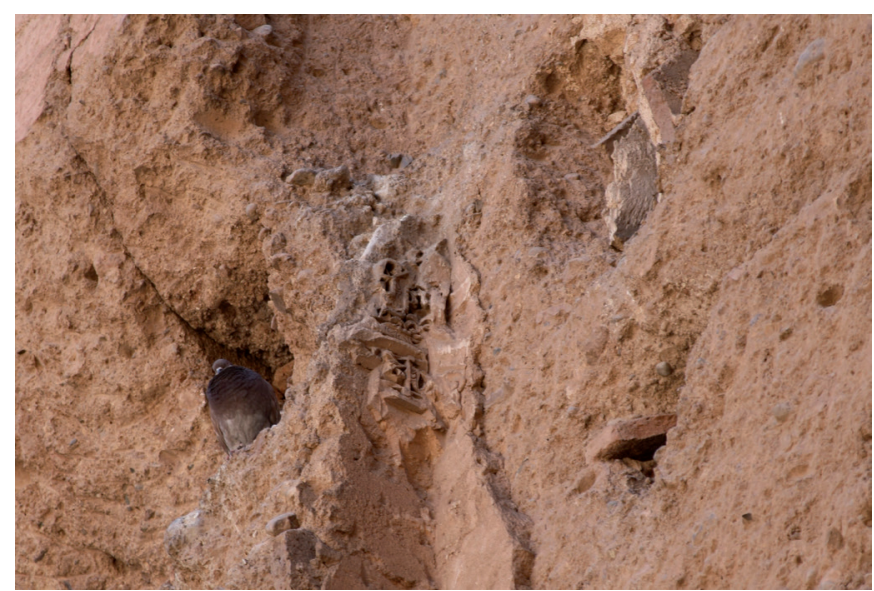

Figura 28. Restos de decoración de yesería del descansillo de la escalera occidental

el muro meridional del salón rectangular conserva la impronta del zócalo de alicatado así como del alicer de madera. Cabe pensar que el espacio restante entre ambos estaría recubierto de yeserías. Los arcos de entrada, de paso a la qubba regia y a las alhanías serían de lambrequines. Ya hemos indicado que el techo debió ser ataujerado, seguramente de cinco paños y sin duda con rica decoración de lacería. Las habitaciones anejas se cubrían con alfarjes. En el ángulo suroeste del salón aún se conserva un resto significativo del pavimento constituido por un fino alicatado (Fig. 27). Los patios tendrían cargaderos de madera con zapatas en sus pórticos siguiendo la tradición de lo almohade y meriní. En un ángulo correspondiente a la parte alta del descansillo de la escalera se ha conservado un pequeño resto de yesería tallada con labor de ataurique (Fig. 28)

Toda la información recogida ha permitido definir con bastante fiabilidad tanto la planta como los alzados 
y secciones del salón en sus líneas generales. Para la altura de las columnas del pórtico hemos supuesto que serían semejantes a las de otros pórticos del palacio y en concreto al del pabellón occidental con columnas pareadas ${ }^{27}$.

Para definir los detalles de la decoración podemos recurrir a la ornamentación de los edificios coetáneos, sobre todo el mausoleo de los sa'adíes y la madraza Ben Yusef, en los que encontramos los mismos materiales y formas que cabe suponer hubo en el palacio: zócalos de alicatado, de los que existen algunos restos en esta sala norte, paramentos recubiertos de yesería, aliceres de madera y arcos de perfil de lambrequines con la composición de arco central de mayor tamaño y arcos menores rematados por paños de sebka.

Las huellas que los elementos de madera han dejado en los muros resultan muy elocuentes permitiendo establecer unas hipótesis generales, y sobre todo, conocer dónde terminaban los paños de yesería y dónde comenzaba la decoración en madera. Desgraciadamente para la forma del techo, no podemos precisar demasiado ya que no hay otros indicios que nos permitan presentar una hipótesis plenamente fiable entre las varias posibles.

Con todos estos datos se ha planteado y dibujado la hipótesis que esperamos sirva para realizar en un próximo futuro la reconstrucción virtual del conjunto a semejanza de la hecha para el pabellón occidental. Como en otros casos, también aquí insistimos en que muchas de las soluciones que proponemos son puras conjeturas que pueden ser revisadas. En todo caso, siendo aproximaciones posibles, facilitan el objetivo ya apuntado en otras ocasiones de suscitar el adecuado debate que nos permita acercarnos a una mejor comprensión del monumento.

\section{La descripción de al-Badi en un texto coetáneo}

De entre los distintos textos coetáneos a la vida del palacio que describen en mayor o menor grado este conjunto merece destacar por la información que nos ofrece el debido a Abu Fares 'Abd-al 'Aziz ibn Muhammad ibn Ibrahim al-Fištali que fue secretario del sultán Ahmad al-Mansur y compuso muchos de los poemas que decoraron las distintas estancias del palacio al-Badi. Resulta del mayor interés analizar la descripción que hizo del palacio y en particular de este Salón Norte en el texto que nos dejón ${ }^{28}$, cuya traducción debo a la cortesía del Prof. Hamid Triki. No obstante, hay que considerar el hecho admitido de que el texto que ha llegado hasta nosotros está desordenado en algunos pasajes, lo que plantea dificultades de interpretación

$\mathrm{He}$ aquí el texto junto con algunos comentarios sobre lo que nos dice:

\section{Al-Dar al-Kubra (la gran residencia) \\ Palacio de la residencia del Imam, construido al lado de la muralla en la muy espaciosa llanura. Posee 20 cúpulas dispuestas simétricamente, con decoraciones pintadas y esculpidas. Estos distintos edificios comprenden diversos mihrabs (alhanias) tamathils (elementos arquitectónicos esculpidos), maqsuras (recintos aislados), maŷazin (alma- cenes o alacenas), maŷlis (salas de recepción).}

\section{La gran qubba oriental: al-Zuŷaziya}

Cubierta de vidrios coloreados difunde una brillante luz proyectada desde su techo labrado en maderas preciosas, llamadas al-ŷullaf, y recubierto de oro resplandeciente. Los ventanales alli abiertos iluminan los muros creando una especie de ambiente paradisíaco.

El suelo está revestido de un mármol de la más pura agua.

En cada una de sus tres puertas se halla un vasto bartal (pórtico), obra monumental de dobles calles soportada por columnas de mármol alargadas como palmeras. Se apoyan en sólidas losas de un trabajo delicadísimo.

Comentario: Por la alusión a los cristales, y las dobles calles de los pórticos, no cabe duda de que se está refiriendo a la qubba al-Zuŷaziyya. También la alusión al recubrimiento de oro del techo permite pensar en la otra denominación de esa qubba, al-Dahbiyya o dorada. El nombre de qubba de cristal podría estar haciendo indicación a la presencia de ventanas con vidrios de colores en la parte alta, a modo de linterna, como es habitual en muchos casos andalusíes. Es cierto que el dibujo de El Escorial no representa ningún hueco, ya que dibuja esta qubba como idéntica a la occidental, cuando en realidad el cuerpo sobresaliente por encima de los pórticos y que correspondía al tamaño de la sala era bastante menor. Tampoco dibuja huecos en la zona alta del Salón Norte donde está comprobado que existieron por lo que en este tipo de detalles no puede considerarse absolutamente fiable.

\footnotetext{
27 Almagro 2013b: fig. 25.
} 


\section{La gran qubba occidental: al-Jamsiniyya}

Esta célebre qubba llamada al-Jamsiniyya, de altura inabarcable, modelo perfecto de su género. Comparada con las otras cúpulas parece la novia asentada sobre el trono de la belleza.

De una parte y otra del gran rafraf (vano de las galerías?) enmarcando la mansión se encuentran dos enormes águilas rodeadas de otras aves de presa con sus alas desplegadas o recogidas. Por su magnifico techo, su belleza, su amplitud y su altura majestuosa que deslumbra la mirada, la cúpula se puede comparar con la bóveda celeste, suspendida como está, sin soporte de columnas, como la omnipotencia del Divino Creador sostiene el cielo sin que éste se abata sobre la tierra. Los enormes techos de estilo berchla (armaduras?) están soportados por vigas de madera y barras de hierro.

Comentario: Es sin duda la estancia principal del palacio y a la que dedica más elogios, en espacial a su techumbre. Es de resaltar la alusión a elementos escultóricos en forma de aves.

\section{El Bahw (alcoba reservada al sultán)}

El Bahw, por la exhibición de su belleza resplandece sobre la qubba. Es desde aqui desde donde se accede al ryad maravillosamente ordenado a través de una puerta ricamente decorada, inscrita entre dos arcos en el mármol más puro, labrado de alveolos de mocárabes y reposando sobre un pedestal de un amarillo claro veteado de un color de ébano.

En el centro del espacioso Bahw de la qubba hay aves cuyas cabezas se dirigen hacia abajo como para cantar la alabanza del soberano.

Comentario: No cabe duda que este $b a h w$ era la sala menor destinada al sultán y situada en el lado oeste del pabellón occidental. La alusión a una puerta de acceso al ryad o jardín haría pensar en una confusión con el pabellón oriental en donde la pequeña alcoba al este de la qubba sí parece que daba acceso al jardín al-Muštaha situado a oriente del palacio, mientras que en el pabellón occidental el bahw sólo tenía acceso a través de la $q u b b a$. De nuevo aquí aparecen aves, al parecer como esculturas.

\section{El bartal (pórtico)}

La Gran Qubba está precedida por un vasto pórtico con numerosos arcos soportados por una línea de columnas dobles asentadas sobre zócalos de mármol labrado. El suelo está revestido de mármol puro. En cuanto a la Manara (el bury descrito a continuación) atrae la mirada por su estructura gigantesca.

Comentario: Aparte de confirmar la presencia de pórtico en el pabellón occidental es interesante la alusión a columnas dobles, confirmadas por los capiteles que aún se conservan en el monumento. También debemos resaltar la información de que el pavimento era de mármol, en contra de nuestra primera hipótesis en que lo supusimos cerámico.

\section{El burŷ, alta torre fortificada}

Para levantar y sostener los techos de la más alta torre, se usaron 700 cargas de enormes maderos de cedro, componiendo cada carga dos maderos. Se emplearon igualmente 100 quintales de hierro. Así es como se coronó la torre lo que permitió a continuación decorar sus techos con toda clase de motivos en forma de sello y otras obras de estilo llamado minqar $y$ muhŷam. La qubba [al-Jamsiniyya] y su hermana llamada Zuŷaziyya (de vidrio) están coronadas con bolas de cobre dorado cuyo brillo casi ciega la mirada. Las dimensiones de las bolas fueron reducidas intencionadamente con respecto a las que coronan el alminar, por el respeto debido a los santuarios dedicados a Alá, el Muy Alto.

Comentario: Esta torre a la que también parece se alude en otra parte del texto de al-Fištali, estaría situada sobre la habitación del sultán y tendría emplazamiento de cañones en su parte alta. Aunque parece estar representada en algunos de los grabados y dibujos existentes, no resulta posible conocer su situación exacta, pues en los restos actuales del palacio no se identifica ninguna estructura que pudiera ser la base de esta torre. Es muy probable que este fragmento esté fuera de su sitio y corresponda a otra zona de la qasba y que por tanto la torre no tenga relación con la qubba Jamsiniyya. Es interesante la descripción de las bolas de cobre dorado que rematan los tejados de las dos qubbas y que confirma lo que se representa en el dibujo de la biblioteca de E1 Escorial.

\section{Las otras dos qubbas del palacio}

A las dos qubbas descritas desafian en belleza otras dos situadas una en frente de la otra a lo largo de los lados del palacio. Una de ella que lleva el nombre de Qubbat al-Nasr (qubba de la victoria) es un ejemplo de obra de arte donde abundan los mihrabs (alhanías), los tamathils (esculturas o pinturas figurativas?), las maqsuras (compartimentos aislados) los oratorios, las alacenas, los maŷazines (alma- 
cenes) y aspiradores para evacuar el humo de los cirios encendidos permanentemente y evitar que oculten las decoraciones.

Comentario: Todo parece indicar que estas otras dos qubbas estaban situadas en el eje perpendicular al de las dos antes descritas y por tanto se trata de los salones existentes en el centro de los lados norte y sur. Sin duda, de estos dos salones el más importante era el del lado norte, que acabamos de estudiar, y por tanto hemos de interpretar que se trata de la mencionada aquí como qubba al-Nasr. La complejidad a la que parece aludir esa presencia de muy distintos tipos de espacios concuerda con la hipótesis que hemos planteado para ese edificio. No es posible saber a que tipo de sistema de ventilación se está refiriendo para la evacuación del humo de las velas. Quizás tuviera relación con la presencia de los patios o con la existencia de ventanas que ventilaban el camaranchón existente entre el techo de la sala y el tejado.

\section{El bahw de la qubba al-Nasr}

Si las cúpulas antes descritas tuvieran que rivalizar en belleza con la qubba al- Nasr, esta podría exhibir su bahw decorado con motivos realizados en marfil y en ébano, y su amplio techo que se cierne a una altura comparable a la de las nubes. De sus crepúsculos emanan colores pintados en amarillo aplicado sobre verde en un fondo blanco. Sus alicatados están tan finamente tallados que se diría trabajados con aguja. Toda esta obra ejecutada en mocárabes habría admirado a los antiguos gigantes de antaño y a los sabios de los antiguos Yunan (griegos de la antigüedad).

Comentario: No cabe duda de que también en este caso el bahw es la alcoba situada en el centro del lado norte del salón y que era el lugar donde se situaba el sultán. Es interesante la referencia a la riqueza de materiales nobles, como marfil y ébano, utilizados en su decoración, lo mismo que a los alicatados de los que ya hemos comentado que quedan restos en varias zonas del edificio.

\section{El bartal (pórtico) de la qubba al-Nasr}

Está situado delante de la qubba, soportado por altísimas columnas de mármol y coronado por una chechia (casquete) muy labrado. Las columnas alli intercaladas son de colores verdes y blancas.

Comentario: la confirmación de la existencia de un pórtico también delante de este salón, no por obvia deja de tener su interés así como la referencia a un casquete decorado como coronamiento del pórtico. Podría tratarse de una cupulilla en el techo del pórtico como la que existe en posición parecida en el palacio del Partal de la Alhambra ${ }^{29}$.

\section{La qubba al-Tî̀an}

Posee varios bahw-s labrados con mocárabes con sus lados policromados con polvo de lapislázuli y salpicado de lentejuelas de oro emana una luz que se refleja en los nichos. Tiene también otros elementos arquitectónicos, oratorios, almacenes, etc. El color aqui dominante es el verde. Enormes columnas soportan una masriyya (sala alta con vistas) con decoración labrada sin pintar.

Comentario: por el orden de la descripción este salón debía ser el situado en el lado sur. Resulta difícil interpretar los detalles del texto en primer lugar por su inconcreción, pero sobre todo porque con la restauración a que fue sometida esta parte del palacio no ha quedado ningún elemento reconocible ni en el suelo ni en los paramentos. De todos modos no parece que fuera tan compleja como la del lado norte, pero pese a ello resulta complicado saber cómo se organizaban todos los elementos que se citan.

\section{Conclusiones}

El estudio que hemos llevado a cabo sobre esta parte del palacio al-Badi nos ha puesto de manifiesto un edifico de notable interés tanto por su originalidad como por la riqueza espacial y decorativa que tuvo que tener con una imagen muy distinta de cómo hoy lo observamos. El expolio y, en este caso, la destrucción de los muros de compartimentación interior del edificio que pudo haberse llevado a cabo en el primer momento del saqueo o en período posterior cuando se adapta el edificio a un uso industrial, transformaron el espacio interior haciendo irreconocible su primitiva forma. Si bien es cierto que en el plano realizado después de la excavación por la Inspección de Monumentos del Protectorado ${ }^{30}$ y otro plano expuesto actualmente en el monumento se recogen algunos de los indicios visibles en el suelo, ninguno de estos documentos plantea una verdadera hipótesis sobre la disposición del salón. Nuestra propuesta configura un espacio principal en forma de sala alargada con alhanías en los extremos, dentro de la tradición andalusí, pero con la particularidad

\footnotetext{
29 Orihuela 1996: p. 61, fig. 21.

30 Meunier 1957: fig. IV.
} 
de la presencia del bahw o pequeña sala de planta cuadrada adosada al espacio principal y destinada al sultán. Este elemento, aunque tiene algún paralelo en la arquitectura de al-Ándalus confiere al conjunto un carácter más relacionado con lo norteafricano e incluso lo oriental. El más inmediato paralelo es sin duda la alcoba o hueco central del lado norte del Salón de Comares, que por la epigrafía allí presente sabemos que estuvo destinada al sultán, aunque en una primera visión del salón parezca una más de las nueve ventanas que tiene a nivel del suelo. También puede considerarse una variante de la asociación de una sala alargada con una qubba presente igualmente en el palacio de Comares, pero también en otros palacios castellanos como el de D. Fadrique en el convento de Santa Clara de Sevilla, el Alcázar Real de Guadalajara o el Cuarto de la Montería del Alcázar de Sevilla ${ }^{31}$. Pero en estos casos, sala y qubba tiene una clara separación como espacios autónomos comunicados por una puerta mientras en este caso lo que se configura es un auténtico salón en T invertida aunque con sistemas de cubrición independientes. Desde este punto de vista, el espacio del salón norte guarda relación con los salones en forma de $\mathrm{T}$ comunes en la arquitectura residencial tanto del norte de África, especialmente en Argelia y Túnez (Fig. 29) ${ }^{32}$, como en Siria ${ }^{33}$. Aunque el resultado en planta sea similar, el origen de esta forma parece distinto para oriente, en donde surge de un espacio central, originalmente un patio con iwanes en tres de sus lados que se acaba cubriendo con linterna, que para occidente, en donde su desarrollo parte de la sala alargada a la que se une un espacio agregado que adquiere carácter preeminente ${ }^{34}$. Este modelo de sala en T se extendió y generalizó en toda el área de influencia del imperio otomano.

En al-Badi' el espacio dedicado al sultán, o lo que es lo mismo, el brazo vertical de la $\mathrm{T}$, adquiere un papel protagonista que sin duda estaría enfatizado por la decoración. Es interesante comprobar la existencia de estos bahws o espacios regios en todas las estancias principales del palacio, tanto en las dos grandes qubbas que se proyectan hacia el patio, como en los salones de los lados norte y sur. Aunque en la qubba oriental el bahw parezca un espacio de paso, no debe ignorarse su carácter

\footnotetext{
31 Almagro 2008: pp. 67, 72, 85.

32 Por ejemplo Dar Otman de Túnez (Revault 1980: p. 58) o Dar Aziza de Argel (Missoum 2010: p. 169). En estas zonas el espacio preeminente de la sala en $T$ recibe el nombre de $q b u$, derivado de la palabra qubba (Revault 1980: p. 53, Missoum 2010: pp. 159-160).

33 Por ejemplo el Palacio Azem de Damasco o casas de Alepo (Petruccioli 2007: p. 97).

34 El caso más antiguo es seguramente el palacio de Ašir, en Argelia (Golvin 1957: pp. 180-182).
}

preeminente al ser el lugar desde el que se controla la $q u b b a$, el patio con sus parterres y albercas, y también el jardín al-Muštaha ${ }^{35}$ situado en un plano inferior a oriente del palacio (Fig. 1).

La presencia del bahw se produce tanto junto a $q u b$ bas de planta cuadrada como en combinación con salones alargados, lo que crea un modelo arquitectónico con clara vinculación a la presencia del sultán que sabemos gustaba ocultarse de la vista de sus súbditos detrás de una cortina ${ }^{36}$, siguiendo formas protocolarias ya adoptadas por otras dinastías, y cuya materialización podría hacerse fácilmente en estos espacios agregados donde el arco de comunicación podía cerrase con facilidad mediante un cortinaje. Todo esto nos hace pensar que este Salón Norte junto con el pabellón occidental eran los espacios de mayor entidad protocolaria de todo el conjunto áulico sa'adí.

En la adopción de estas salas en $\mathrm{T}$ podemos considerar que se manifiesta una distinción entre este palacio y sus predecesores andalusíes, estableciendo un paso intermedio entre el modelo de sala alargada con qubba adyacente, propio de los ejemplos antes mencionados, hacia la sala en $\mathrm{T}$ con los brazos casi idénticos propio de los modelos orientales y que acabó difundiéndose en el norte de África a partir del período otomano. En al-Badi' el espacio destinado al sultán parece mantener cierta autonomía determinada por la diferencia de tamaño con el resto de la sala, y por disponer de un techo igualmente independiente. En el período inmediatamente posterior, especialmente en los palacios que Muley Ismail construyó en Mequinez, parece seguirse una pauta similar, según se puede ver en la sala oriental de la Dar al-Sultán dentro de la Dar al-Madraza ${ }^{37}$ o en las salas norte y este del patio principal de la Qasr al-Muhannaša ${ }^{38}$. Es de resaltar en este último caso una similitud con al-Badi', tanto en lo que se refiere a sus grandes dimensiones como a la disposición de un jardín en situación parecida al de al-Muštaha del ejemplo que estudiamos. También los pórticos delante de las salas integrados en la crujía general que bordea el patio parecen seguir pautas compositivas semejantes.

Como ya hemos tenido ocasión de indicar en otro trabajo anterior ${ }^{39}$, el palacio al-Badi' constituye un ejemplo sobresaliente de la arquitectura áulica enmarcada dentro de la tradición desarrollada en al-Ándalus desde el periodo califal, que aquí recobra un carácter monumental

\footnotetext{
Mouline 2009: p. 143.

36 García-Arenal 2009: pp. 118-119.

37 Barrucand 1985: p. 43, Plano III, K 13.

38 Barrucand 1985: p. 48, Plano IV, N20 y L23.

39 Almagro 2013b: pp. 15-18.
} 


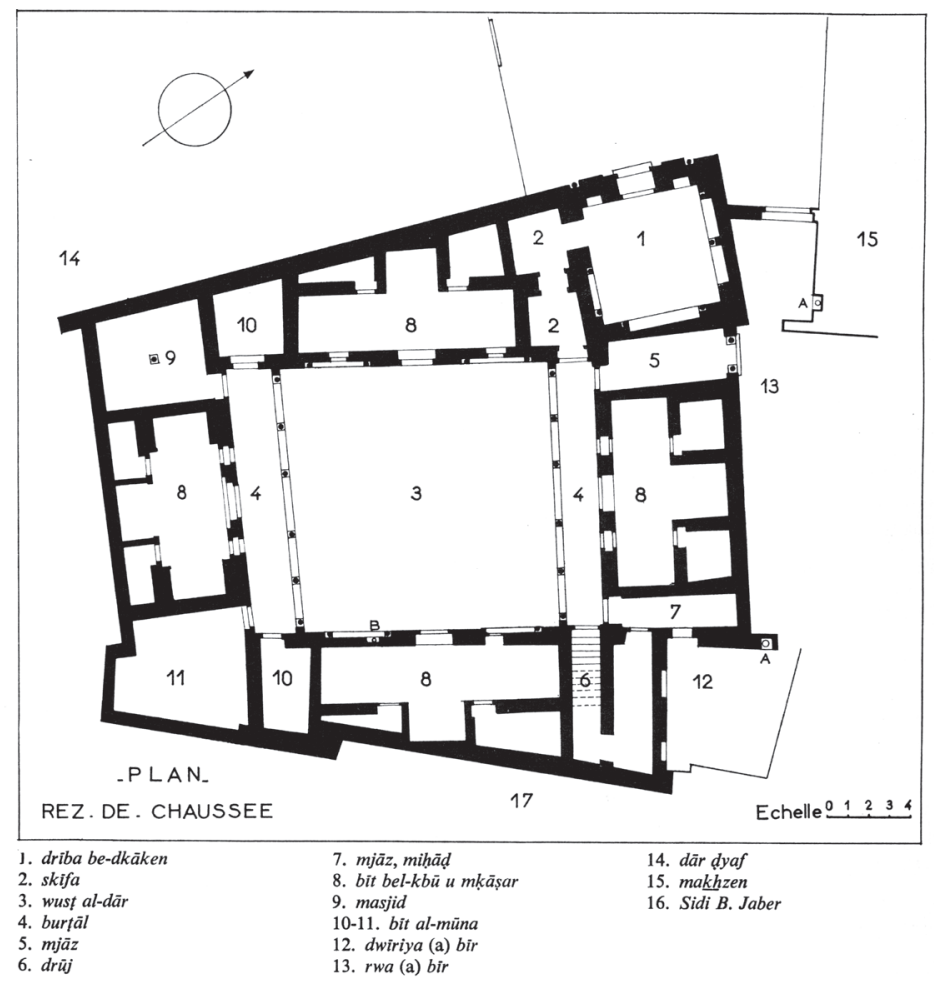

Figura 29. Salones en T de Dar Otman en Túnez (Revault 1980) y de escala comparables a los de Madinat al-Zahra', tanto por la extensión de los jardines como por el tamaño y diversidad de los salones y espacios de aparato. En este sentido el palacio de al-Mansur posee la grandeza de las obras califales, recuperando el sentido de originalidad creativa que en buena medida se diluye tras la desmembración del califato cordobés, pero que aquí reaparece por vía de las ansias imperiales de su promotor, que supo conjugar la tradición andalusí con modelos propios de otras zonas del mundo musulmán que sin duda pensó que podían ayudarle en la escenificación de sus ideas del poder. La adopción de salas o salones en forma de $\mathrm{T}$, que ofrecen un espacio más jerarquizado y representativo que los, en gran medida, anodinos salones alargados característicos de la arquitectura de al-Ándalus, y cuyo ejemplo representativo es este Salón Norte del palacio que hemos estudiado, aportan un cierto aire de renovación a aquella arquitectura cuyo tradicionalismo sólo se había llegado a refrescar con las obras acometidas por el sultán nazarí Muhammad V, de una de cuyas creaciones más singulares e innovadoras, el Palacio de los Leones de la Alhambra, este conjunto áulico resulta tan claramente acreedor ${ }^{40}$.

Es de lamentar, en todo caso, la falta de elementos comparativos del periodo almorávide y almohade que

\footnotetext{
40 Marçais 1954: p. 396; Almagro 2013b: p. 17.
}

nos permitieran presentar un panorama más homogéneo en nuestro conocimiento de la arquitectura palatina medieval en el occidente islámico. Ni los escasos ejemplos murcianos ni los pocos ejemplos conservados en Sevi1la, pero, sobre todo, la casi nula información de que disponemos sobre las residencias regias de este período en Marrakech nos consienten conocer cuánto debe a ellos el palacio al-Badi'. No es mayor la información de que disponemos del período meriní, de cuyos palacios podrían subsistir restos dentro de las actuales residencias reales de Fez, aunque nada podemos decir al respecto. Tampoco favorece el adecuado enmarque de esta obra la desaparición del resto del palacio sa'adí de la qasba marrakusí así como la casi total destrucción del núcleo residencial que sin duda existió en la otra gran creación de al-Mansur, la almunia de la Masarra ${ }^{41}$, en la actual finca del Agdal, tan celebrada por escritores y viajeros contemporáneos y posteriores hasta su abandono y ruina con el cambio de dinastía. Esperemos que futuras investigaciones en estas áreas puedan aportar nueva información que nos permita tener una visión más amplia sobre la arquitectura del periodo sa'adí, cuyo estudio general está aún por abordar.

\footnotetext{
${ }^{41}$ Las primeras investigaciones de los restos de las edificaciones allí levantadas parecen apuntar a una construcción de gran envergadura y originalidad (Navarro et al. 2013: pp. 7-10).
} 
ANEXO

Se acompaña el modelo 3D en la versión html on line.

\section{Bibliografía}

Aimel, G. 1918: “Le palais d'el Bedi’ à Marrakech et le mausolée des chorfa saadiens", Archives berbères, 3, pp. 53-63.

Almagro, A. 2008: Palacios medievales hispanos. Madrid.

Almagro, A. 2011: "Photogrammétrie pour la recherche architecturale: vingt ans d'expérience à l'École d'Études Arabes", Revue Française de Photogrammétrie et Télédétection, 196, pp. 10-20.

Almagro, A. 2013a: "Surveying World Heritage Islamic Monuments in North Africa”, ISPRS Annals Photogramm. Remote Sens. Spatial Inf. Sci., II-5/ W1, pp. 13-18. http://www.isprs-ann-photogramm-remote-sens-spatialinf-sci.net/II-5-W1/13/2013/isprsannals-II-5-W1-13-2013.pdf

Almagro A. 2013b: "Análisis arqueológico del pabellón occidental del palacio al-Badi' de Marrakech”, Arqueología de la Arquitectura, 10: e008. doi: http://dx.doi.org/10.3989/arq.arqt.2013.002

Almagro, A., Navarro, J. y Orihuela, A. 2008: "Metodología en la conservación del patrimonio arquitectónico medieval", en Saiz-Jiménez, C., Rogerio-Candela, M.A. (eds.), La Investigación sobre Patrimonio Cultural, pp. 87-98. Sevilla.

Almagro-Vidal, A. 2008: El concepto de espacio en la arquitectura palatina andalusí. Un análisis perceptivo a través de la infografia. CSIC, Madrid.

Barrucand, M. 1985: Urbanisme princier en Islam. Meknès et les villes royales islamiques post-médiévales. Paris.

Cabanelas Rodríguez, D. 1988: El techo del Salón de Comares de la Alhambra. Decoración, Policromía, Simbolismo y Etimología. Granada.

Deverdun, G. 1959: Marrakech, des origines à 1912, 2 vols. Rabat.

Estelle, J.B. 1931: "Mémoire adressé à Monseigneur de Maurepas, 2 avril 1698”, en Les Sources Inédites de l'Histoire du Maroc, Deuxième série, Dynastie Filaelienne, France, t. IV, pp. 384-408. Publicadas por P. de Cenival, Paris.

Al-Fistali, 'Abd al-'Aziz 1964: Manahil al-Safa fi ma'atir mawali-na alsurafa. Ed. 'Abdallah Guennun, Rabat: Faculté des Lettres, y Tétouan: Institut Moulay El-Hassan.
García-Arenal, M. 2009: Ahmad al-Mansur: The Beginnings of Modern Morocco. Oxford.

Golvin, L. 1957: Le Magrib Central à l'Époque des Zirides. Paris.

Al-Ifrani, Muhammad Sagir 1889: Nozhet-Elhâdi, histoire de la dynastie saadienne au Maroc (1511-1670), par Mohammed Esseghir ben Elhadj ben Abdallah Eloufrâni, traduction française par O. Houdas. Ernest Leroux, Paris.

Koehler, H. 1940 : "La Kasba saadienne de Marrakech, d'après un plan manuscrit de 1585", Hespéris, XXVII, pp. 1-20.

Marçais, G. 1954 : L'architecture musulmane d'Occident. Tunisie, Algérie, Maroc, Espagne, Sicile. Paris.

Meunier, J. 1957: "Le Grand Riad et les bâtiments saadiens du Badi selon le plan publié par Windus”, Hespéris, XLIV, pp. 129-134.

Missoum, S. 2010: "La vivienda tradicional en la cuenca del Mediterráneo: del iwan al kbu, pasando por el bahw", en Cressier, P., Montilla Torres, I., Sánchez Viciana, J.R. y Vallejo Triano, A., Miscelánea de historia y cultura material de al-Ándalus. Homenaje a Maryelle Bertrand, Cuadernos de Madinat al-Zahra', 7, pp. 149-173.

Mouline, N. 2009: Le califat imaginaire d'Ahmad al-Mansur. Pouvoir et diplomatie au Maroc au XVI siècle. Paris.

Navarro Palazón, J., Garrido, F., Torres, J.M., Triki, H. 2013: “Agua, arquitectura y poder en una capital del Islam: el Agdal de Marrakech (ss. XII-XX)", Arqueología de la Arquitectura, 10: e007. doi: http://dx.doi. org/10.3989/arq.arqt.2013.014

Nuere, E. 1989: La carpintería de armar española. Madrid.

Orihuela Uzal, A. 1996: Casas y palacios nazaries. Siglos XIII-XV. Lunwerg, Barcelona.

Petruccioli, A. 2007: After Amnesia, Learning from the Islamic Mediterranean Urban Fabric. Bari.

Puerta Vílchez, J.M. 2011: Leer la Alhambra. Guía visual del monumento a través de sus inscripciones. Granada.

Revault, J. 1980 : Palais et demeures de Tunis (XVI -XVII siècles). Paris.

Triki, H. y Dovifat, A. 1999: Medersa de Marrakech. Marrakech.

Windus, J. 1725: A journey to Makinez; The Residenz of the Present Emperor of Fez and Marocco on the Occasion of Commodore Stewart's Embassy thither for the Redemtion of the British Captives in the year 1721. London. 